\title{
Chitin in Strawberry Cultivation: Foliar Growth and Defense Response Promotion, but Reduced Fruit Yield and Disease Resistance by Nutrient Imbalances
}

\author{
C. De Tender,$^{1,2,+}$ B. Vandecasteele, ${ }^{1}$ B. Verstraeten,${ }^{3}$ S. Ommeslag, ${ }^{1}$ T. De Meyer, ${ }^{4,5}$ J. De Visscher, ${ }^{1,3}$ \\ P. Dawyndt, ${ }^{2}$ L. Clement, ${ }^{2,5}$ T. Kyndt, $^{3}$ and J. Debode ${ }^{1}$ \\ ${ }^{1}$ Plant Sciences Unit, Flanders Research Institute for Agriculture, Fisheries and Food, Burgemeester Van Gansberghelaan 92, \\ 9820 Merelbeke, Belgium \\ ${ }^{2}$ Department of Applied Mathematics, Computer Science and Statistics, Ghent University, Krijgslaan 281 S9, 9000 Ghent, \\ Belgium \\ ${ }^{3}$ Epigenetics \& Defence Research Group, Department Biotechnology, Ghent University, Coupure Links 653, 9000 Ghent, \\ Belgium \\ ${ }^{4}$ Department of Data Analysis \& Mathematical Modelling, Ghent University, Ghent, Belgium \\ ${ }^{5}$ Bioinformatics Institute Ghent From Nucleotides to Networks, Ghent University, 9000 Ghent, Belgium
}

Accepted 29 October 2020.

Strawberry cultivation is associated with high mineral fertilizer doses and extensive use of chemical plant protection products. Based on previous research, we expected that chitin application to peat substrate would increase the nutrient availability and activate the plant systemic defense response, resulting in higher strawberry yields and fewer disease symptoms. We set up two experiments in which the temporal variability and differences in initial nutrient concentrations of the growing media were taken into account. Chitin treatment resulted in the attraction of plant growth-promoting fungi toward the plant root, such as species from genera Mortierella and Umbelopsis. In addition, by the end of the experiments $87 \mathrm{mg}$ of mineral nitrogen $(\mathrm{N})$ per liter of substrate was mineralized, which can be related to the observed increase in plant shoot biomass. This, however, led to nutrient imbalances in plant shoots and fruit; $\mathbf{N}$ concentration in the leaves increased over $30 \%$, exceeding the optimal range, while phosphorous $(P)$ and potassium $(K)$ deficiencies occurred, with concentrations lower than $50 \%$ of the optimal range. This may explain the decreased fruit yield and disease resistance of the fruit toward Botrytis cinerea. In contrast, chitin caused a clear defense priming effect in the strawberry

T. Kyndt and J. Debode contributed equally to this work.

${ }^{\dagger}$ Corresponding author: C. De Tender;

caroline.detender@ilvo.vlaanderen.be

Funding: This research was funded and executed within the Horti-BlueC project. This project received funding from the Interreg 2 Seas Programme 2014-2020 co-funded by the European Regional Development Fund under subsidy contract number 2S03-046. Both the Province of Antwerp and the Province of East-Flanders are co-funding ILVO for Horti-BlueC. C. De Tender received a grant of the Research Foundation Flanders (FWO) with application number $12 \mathrm{~S} 9418 \mathrm{~N}$.

*The $\boldsymbol{e}$-Xtra logo stands for "electronic extra" and indicates there are supplementary material and supplementary table files published online.

The author(s) declare no conflict of interest. Cop)(1) (-)
Copyright ( $) 2021$ The Author(s). This is an open access article
distributed under the CC BY-NC-ND 4.0 International license. leaves, with a strong induction of the jasmonic acid response, resulting in fewer foliar disease symptoms. Chitin causes positive effects on shoot growth and foliar disease resistance, but caution needs to be taken for nutrient imbalances leading to negative influences on root growth, fruit production, and disease susceptibility toward $B$. cinerea.

Keywords: chitin, Fragaria ananassa, growth promotion, metabarcoding, priming, RNA sequencing

In the last two decades, worldwide strawberry production increased by $55 \%$ to a production of 9.2 million tons in 2017 (FAOSTAT 2019; Hancock et al. 2008). To increase turnover, strawberries are cultivated both in open soil and soilless media. Soilless cultivation depends on fertigation with mineral fertilizers to supply the crop with sufficient nutrients (Vandecasteele et al. 2018). These mineral fertilizers have a cost on the environment (Basosi et al. 2014; Hasler 2017), and reduction of their use is recommended.

Strawberry plants and fruit are highly susceptible to diseases (Paulus 1990). Botrytis cinerea infection leads to disastrous economic losses for many important fruit or vegetable crops. $B$. cinerea is the second most significant fungal pathogen worldwide, with high risk for fungicide resistance (Petrasch et al. 2019), and is used as a model for fungal necrotrophic pathogens (Dean et al. 2012). To prevent the occurrence of diseases, chemical plant protection products are often used in horticulture. For strawberry cultivation, multiple active plant protection product residues can be found on the fruit (Vervoort et al. 2017).

The need for environmentally friendly alternatives for mineral fertilizers and chemical plant protection in strawberry cultivation is, thus, high. One of the alternatives of interest is chitin, an $\mathrm{N}$-acetylglucosamine polymer. Chitin is considered as the second most abundant polysaccharide on Earth (Gooday 1990), with a global yearly production of 1.5 million tons of chitinous waste, $12 \%$ originating from the global fish industry (e.g., crab and shrimp shells) (Ramírez et al. 2010).

In agriculture, chitin can be used to improve crop yield. Several studies have shown the benefits of chitin supply to soil in terms of plant protection and crop growth. For instance, 
addition of chitin to field soil decreases infection rates of plant roots by parasitic nematodes (Radwan et al. 2012; Sarathchandra et al. 1996) and induces host resistance against the fungal soil-borne pathogens Verticillium dahliae and Rhizoctonia solani (Inderbitzin et al. 2018; Postma and Schilder 2015). Furthermore, the application of chitosan, a chitin derivative, improves the growth of crops such as tomato, soybean sprouts, sweet basil, and grapevine (Ait Barka et al. 2004; Algam et al. 2010; Kim et al. 2005; Lee et al. 2005).

In contrast to soil ecosystems, the knowledge of chitin properties in soilless plant cultivation is still limited. Our previous research showed that addition of chitin can improve lettuce growth (Debode et al. 2016) by increasing nitrogen (N) availability in the peat substrate (PS) (De Tender et al. 2019). Chitin application in substrate reduces belowground plant infections, such as Phytophthora fragariae infection on Fragaria vesca (Rafferty et al. 2003), as well as the survival of the aboveground zoonotic pathogen Salmonella enterica on lettuce leaves (Debode et al. 2016). Chitin can induce plant systemic resistance. As parts of, e.g., fungal cell walls and nematode egg masses, chitin oligomer fragments are detected by "chitin elicitor-binding protein" receptors on the plasma membrane, which will result in an activation of a plant defense response. Chitin and its derivatives, such as chitosan, are therefore often reported as pathogen-associated molecular patterns (PAMP) (Sánchez-Vallet et al. 2015; Sharp 2013).
In the current study, we test if chitin can be used in soilless strawberry cultivation to increase plant growth and fruit production and increase plant defense against $B$. cinerea, reducing the need for mineral fertilization and plant protection products. First, we hypothesize that chitin-induced growthpromoting effects are due to the release of plant-available $\mathrm{N}$ (ammonium-N or nitrate-N) in the PS. Higher concentrations of mineral fertilizers in the substrate mixture would thus reduce the chitin effect. To verify this hypothesis, two experiments were set up: i) a time-course experiment for which plant growth, nutrient concentrations in the growing media, and nutrient content of strawberry (Fragaria ananassa) leaves and fruits were measured temporally; and ii) a fertilizer-dose experiment with three different fertilizer dosages (Fig. 1). Second, we presumed that elevated amounts of plant-available $\mathrm{N}$ are released by high-abundant chitin-degrading microorganisms when the substrate is supplied with chitin. Therefore, chitin-induced changes in the bacterial and fungal community in the bulk PS (BS) and the plant rhizosphere were monitored temporally by metabarcoding. Finally, since chitin is known as a PAMP that induces plant immunity, lower disease incidence on strawberry leaves and fruit after $B$. cinerea infection was expected. Therefore, disease incidence and differential expression of plant-defense genes was measured by reverse transcription quantitative PCR (RT-qPCR) and RNA sequencing.

\section{TIME COURSE}

\section{Growing media}

- 西西

x 6 replicates/week 11 weeks

\section{FERTILIZER DOSE}

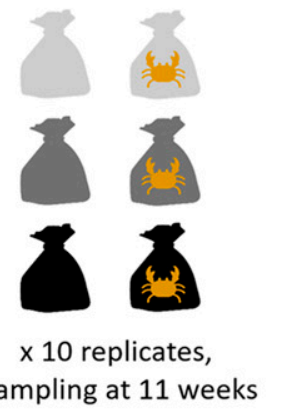

sampling at 11 weeks

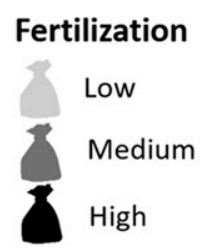

Treatment

Chitin

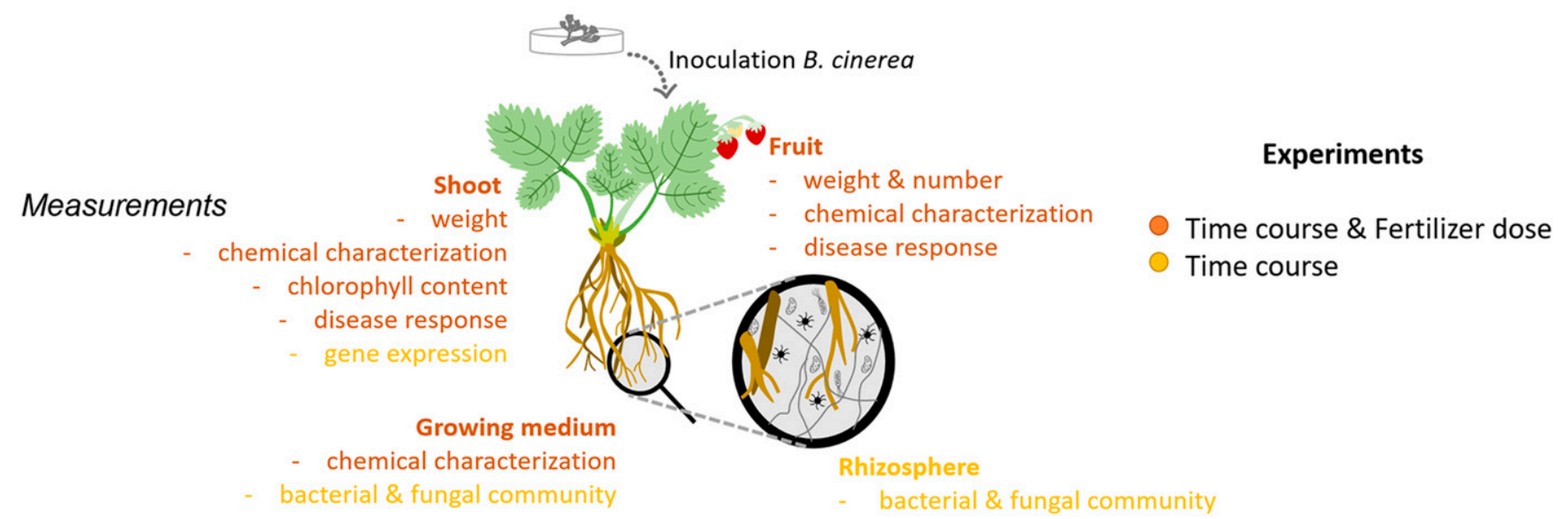

Fig. 1. Experimental design of the time-course and fertilizer-dose experiment. Strawberry plants are grown in mere peat substrate (PS) or PS amended with $2 \mathrm{~g}$ of chitin per liter. In the fertilizer-dose experiment, a low (no additional fertilizer), medium $(0.35 \mathrm{~g}$ of fertilizer per liter) or high ( $1.05 \mathrm{~g}$ of fertilizer per liter) dose of fertilizer has been added. For both experiments, the plant physiological parameters measured were shoot and root weight, chlorophyll content, and fruit yield. In addition, both plant shoots and fruits were chemically analyzed. Furthermore, the disease response toward the fungus Botrytis cinerea was measured for both experiments, by which, in the time-course experiment, plant defense gene expression of the plant shoots was monitored. Belowground, the growing medium was chemically analyzed for both experiments and the shifts of the bacterial and fungal community over time and due to chitin treatment were measured. 


\section{RESULTS}

In this study, we first evaluated the effect of chitin on plant growth and fruit development in relation to nutrient release in the growing medium and nutrient uptake by plant shoots and fruit, respectively. This was done temporally (time-course experiment) and under different fertilizer dosages (fertilizer-dose experiment) (Fig. 1). Second, a potential abundance shift toward more chitin-degrading bacteria or fungi in the BS and plant rhizosphere was studied (time-course experiment). Third, the effect of chitin on disease susceptibility of strawberry plant leaves and fruit toward B. cinerea was studied and related to the plant defense response measured by RT-qPCR and RNA sequencing.

\section{Improved shoot traits but reduced root biomass and fruit yield upon chitin treatment.}

During the first 7 weeks of plant growth, the plant fresh weight (FW) and dry weight (DW) increased by the formation of fresh leaves and fruit. Chitin addition to the PS (PS+CH) resulted in a small but significant increase in total plant shoot weight (FW and DW) from week 7 onwards (generalized additive model [GAM], $P<0.05$ ) (Fig. 2A; Supplementary Fig. $S 1)$ in the time-course experiment. In contrast, no effect was noted in the fertilizer-dose experiment (Wilcoxon test, $P=$ 0.10) (Fig. 2B), and this for each fertilizer dose. Plant leaves contained more chlorophyll in chitin-supplemented peat, from the first week of the experiment onwards (GAM, $P<0.05$ ) (Fig. 2A).

In contrast to the green plant parts, the root weight was significantly lower in the $\mathrm{PS}+\mathrm{CH}$ grown plants (GAM, $P<0.05$ ), from week 7 of plant growth onwards (Fig. 2A).

Fruit development was negatively influenced by chitin application. A significantly lower number of fruits was obtained at 9 weeks of growth (Fig. 2A). These fruits were, on average, smaller compared with those grown in mere PS, with significant decreases in fruit FW in week 6 to 7 in the timecourse experiment (Fig. 2A) and in week 7 to 8 in the fertilizer-dose experiment (Fig. 2C). The total yield over all pots of PS+CH-grown strawberries was about $500 \mathrm{~g}$ lower compared with PS-grown strawberries in the time-course experiment (Fig. 2A). In general, higher fertilization did not result in more fruit, but fruit was appearing and ripening faster (Fig. 2C).

\section{Chitin increases the total amount of plant-available $\mathbf{N}$ in PS.}

We hypothesized that chitin-induced growth promotion of the foliar tissues is, at least in part, the result of higher nutrient concentrations in the growing medium. To verify this hypothesis, the chemical composition of the growing media (PS, $\mathrm{PS}+\mathrm{CH}$ ) was determined for pots with plants (weekly over
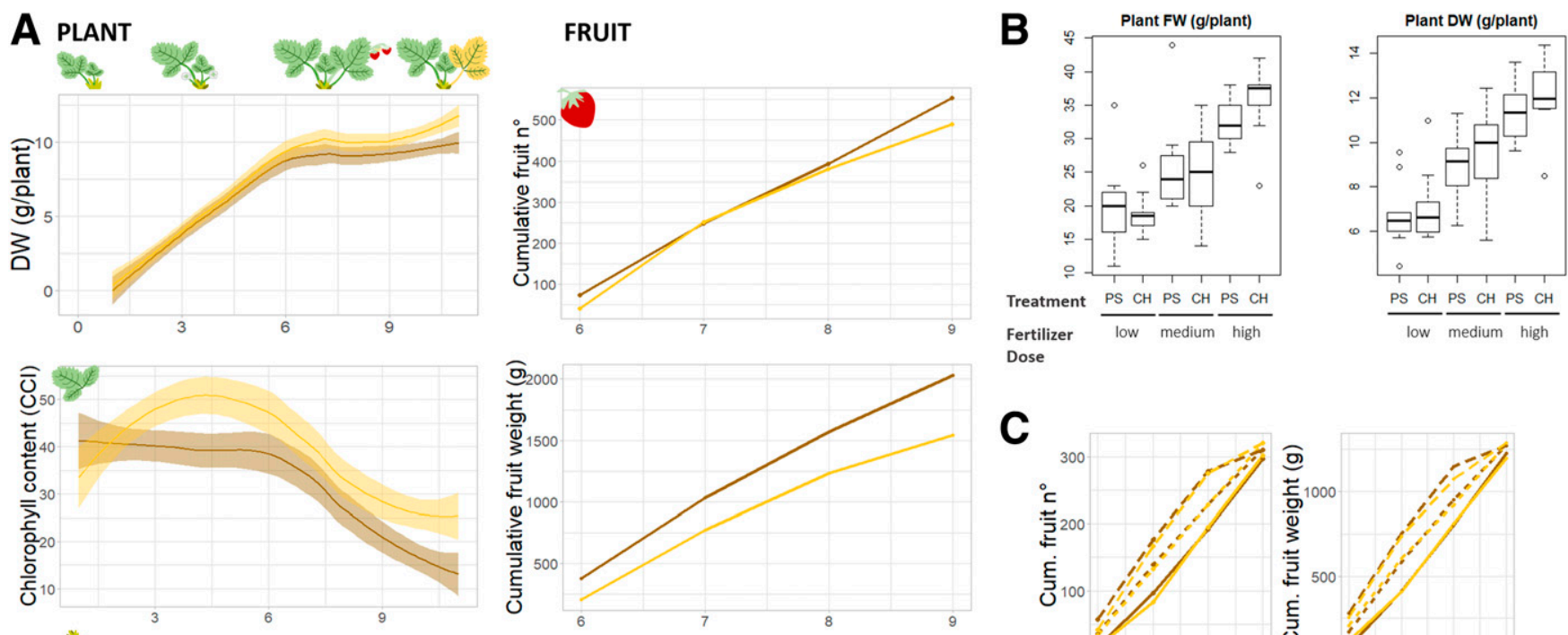

Dose
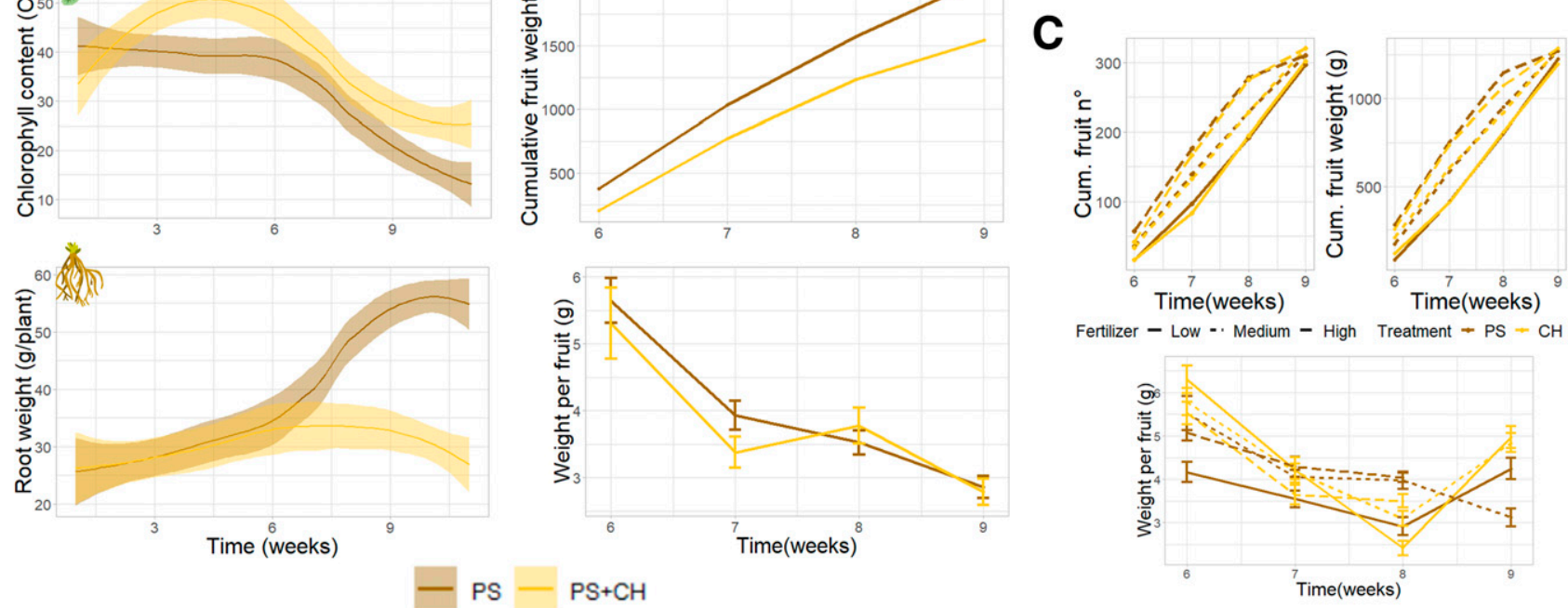

Fig. 2. Effects of chitin application in peat substrate (PS) on strawberry plant and root growth, and fruit yield. A, The plant fresh weight, chlorophyll content, and root weight (left) and the fruit yield in terms of cumulative number of fruits and fruit weight over all pots (right) during 11 weeks of plant growth in either unamended PS (brown) or chitin-amended PS (PS+CH) (yellow) in the time-course experiment. A positive influence of chitin application on plant fresh weight (FW) (grams of FW per plant) was noted in the last four weeks of plant growth (upper left). The chlorophyll content (middle left) was significantly increased from the second week of plant growth onwards. In contrast, root growth (lower left) was limited in chitin-PS grown strawberry plants. For all figures $95 \%$ confidence intervals are shown as shaded areas. Data are represented as mean values \pm standard errors for weight per fruit (right). B, Boxplots representing the plants FW (grams of FW per plant) and dry weight (DW) (grams of DW per plant) of the fertilizer-dose experiment is shown $(n=6)$. C, The cumulative number of fruits and fruit weight over all pots, and the weight per fruit (grams of FW per fruit) of the fertilizer-dose experiment. Values of the weight per fruit are indicated as mean values \pm standard errors. 
11 weeks) and for pots without plants (at 3, 6, 9, and 11 weeks) in the time-course experiment. Both with and without plants, chitin significantly increased the $\mathrm{pH}$ of the substrate in the first 6 to 7 weeks ( $\mathrm{lm}, P<0.001$ for all timepoints), after which it lowered to an average value of 4.7 (Fig. 3A; Supplementary Table S1). The concentration of plant-available $\mathrm{N}\left(\mathrm{NO}_{3}-\mathrm{N}\right.$ and $\mathrm{NH}_{4}-\mathrm{N}$ ) in the PS increased but was only significant for pots without plants, as values dropped below detection level rapidly for pots with plants, indicating active $\mathrm{N}$ uptake by the crop (Fig. $3 \mathrm{~A})$. The increase in $\mathrm{NH}_{4}-\mathrm{N}$ concentration was observed for all points in time $(1 \mathrm{~m}, \mathrm{P}<0.001)$, whereas the $\mathrm{NO}_{3}-\mathrm{N}$ concentration was solely higher from week 9 onwards $(1 \mathrm{~m}, P=0.005)$. A dose of $2 \mathrm{~g}$ of chitin per liter of PS contains $142 \mathrm{mg}$ of total $\mathrm{N}$ (Supplementary Table $\mathrm{S} 2$ ). The net $\mathrm{N}$ release due to chitin amendment in weeks $3,6,9$, and 11 was, respectively, 13.5, $18.4,79.9$, and $87 \mathrm{mg}$ of mineral $\mathrm{N}$ per liter of substrate. Thus, at the end of the experiment, $62.7 \%$ of the total $\mathrm{N}$ in the chitin was mineralized. In addition, addition of chitin decreased the easily available phosphorous $(\mathrm{P})$ (below detection limit for $\mathrm{PS}+\mathrm{CH})$, magnesium $(\mathrm{Mg})$, calcium $(\mathrm{Ca})$, and potassium $(\mathrm{K})$ concentration at the first 3 weeks of the experiment in pots with plants (Fig. 3A; Supplementary Fig. S2), whereas the concentration of easily available carbon increased in the first 4 weeks of the experiment $(\mathrm{lm}, P<0.05)$. Also, for pots without plants, lower water-extractable $\mathrm{P}$ concentrations were observed after chitin amendment in the first weeks of the experiment, indicating that an interaction between chitin and $\mathrm{P}$ rather than higher $\mathrm{P}$ uptake by the plant is the reason for the lower $\mathrm{P}$ availability in the growing medium (Fig. 3A).

In accordance with the time-course experiment, no significant differences in PS chemical composition was noted, at the end of the fertilizer-dose experiment, due to chitin addition for all fertilizer doses (Supplementary Tables S1 and S3). The low concentrations indicate that available nutrients were actively taken up by plants during both experiments.

\section{Chitin increases $\mathbf{N}$ concentration and uptake but decreases $P$ uptake in strawberry leaves and fruit.}

The lower fruit yield of strawberries grown in chitinamended PS might be due to the quick decline in $\mathrm{NH}_{4}-\mathrm{N}$ and $\mathrm{NO}_{3}-\mathrm{N}$ concentrations (PS and $\mathrm{PS}+\mathrm{CH}$ ) and low $\mathrm{P}$ availability in the growing media. To verify this hypothesis, we analyzed the nutrient concentration in strawberry fruit and leaves. In both experiments, the leaf $\mathrm{N}$ concentration increased when chitin was added to PS and this at all points in time (Fig. 3B, Supplementary Table S4). In contrast, $\mathrm{P}$ concentrations in weeks 6 and $9(\mathrm{~lm}, P<0.05)$ were lower in $\mathrm{PS}+\mathrm{CH}$. Besides the $\mathrm{N}$ increase and $\mathrm{P}$ decrease, the concentration of $\mathrm{Mg}$ in the plant leaves increased significantly $(P<0.01,1 \mathrm{~m})$ from $2.99 \mathrm{~g}$ per kilogram of dry matter (DM) to $3.79 \mathrm{~g}$ per kilogram of DM when chitin was added. This effect was only noted when low doses of fertilizer were added to the PS (Supplementary Tables
A
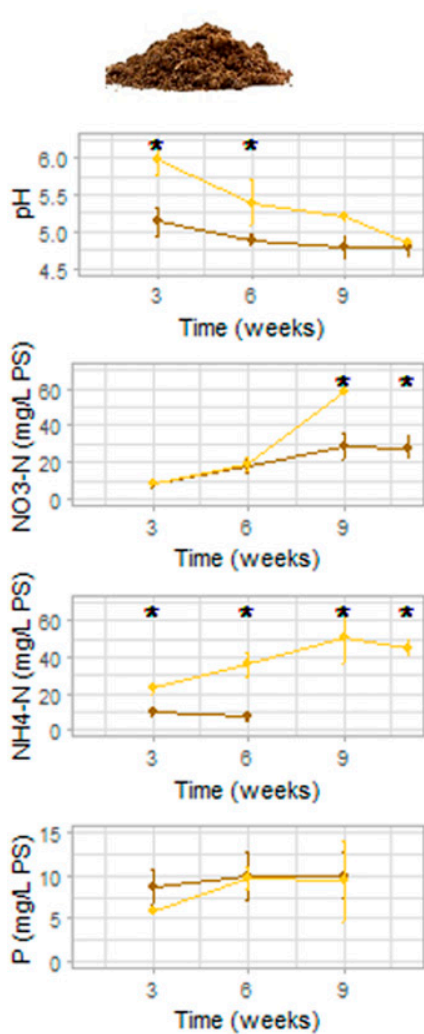

Treatment $\rightarrow$ PS $\rightarrow \mathrm{PS}+\mathrm{CH}$
B

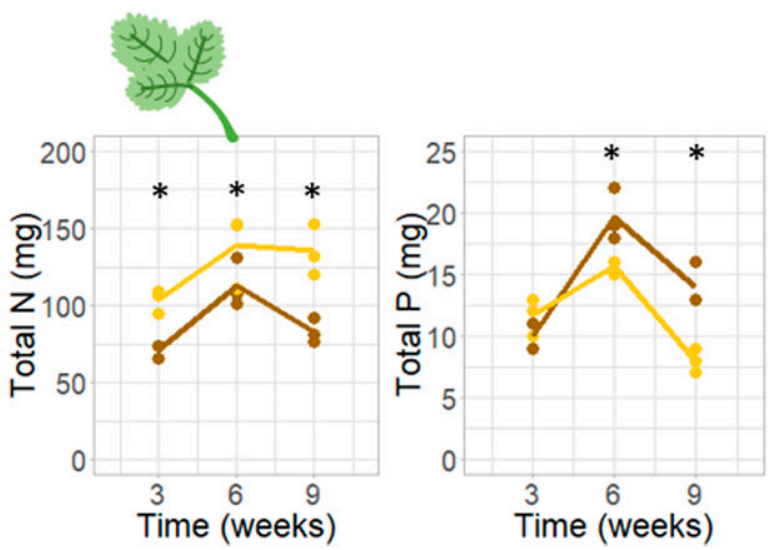

C
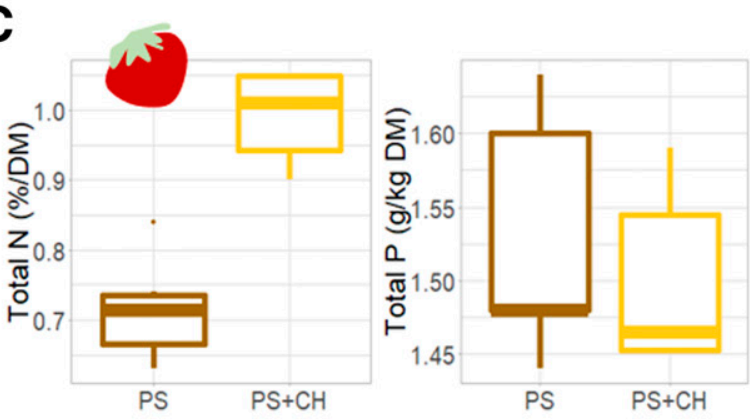

Fig. 3. Chemical characterization of the peat substrate (PS) with plants, strawberry fresh leaves, and strawberry fruit in the time-course experiment over 11 weeks of plant growth. A, pH, plant-available nitrogen $(\mathrm{N})\left(\mathrm{NO}_{3}-\mathrm{N}\right.$ and $\left.\mathrm{NH}_{4}-\mathrm{N}\right)$, and phosphorous $(\mathrm{P})$ concentrations of either of the PS mixtures (without or with $2 \mathrm{~g}$ of chitin per liter added [PS+CH]) in which no plants were grown (left) or plants were grown (right). Dots represent the mean value with the standard deviation as error bars $(n=3)$. If no values occur, the measurement was below detection limit. B, Total $\mathrm{N}$ and $\mathrm{P}$ content (in milligrams) per plant on weeks 3 , 6 , and 9 of the experiment. Mean values are represented as lines, dots represent the values of the biological replicates $(n=3)$. $\mathbf{C}$, The total concentration of $\mathrm{N}$ (percent dry matter [DM]) and total $\mathrm{N}$ and P uptake (in milligrams) of strawberry fruit are represented $(n=5)$. Replicates are considered as all fruits picked from all plants grown in either PS or PS+CH at one specific timepoint (at 5, 6, 7, 8, and 9 weeks of plant growth). 
$\mathrm{S} 4$ and $\mathrm{S} 5$ ). N, P, and $\mathrm{K}$ concentrations in the leaves are below the optimal range for strawberry, indicating that these elements are limiting plant growth. Total $\mathrm{N}$ uptake in the leaves (Fig. 3B) was higher for $\mathrm{PS}+\mathrm{CH}$, while total $\mathrm{P}$ uptake was lower, pointing to a reduced $\mathrm{P}$ uptake in the case of chitin amendment. Both for $\mathrm{N}$ and $\mathrm{P}$, total amounts in the leaves decreased from week 6 to week 9 , indicating active $\mathrm{N}$ and $\mathrm{P}$ translocation to the fruit for both treatments.

Also, strawberry fruit contained a significantly higher $\mathrm{N}$ concentration $(1 \mathrm{~m} ; P<0.001)$ in $\mathrm{PS}+\mathrm{CH}$ (Fig. 3C). N concentration increased by one-third from $0.71 \% \pm 0.07 \% \mathrm{~N} / \mathrm{DM}$ to $0.99 \% \pm 0.06 \%$. A similar increase was noted in the fertilizer-dose experiment when low or medium fertilization doses were used (Supplementary Table S6). For the other nutrients in the fruit, there were no differences in concentrations (Supplementary Tables S6 and S7). There were no differences between treatments in total $\mathrm{N}$ and $\mathrm{P}$ uptake in the fruit.

\section{Chitin slightly affects rhizosphere bacteria but reshapes the fungal community with a rise of Mortierellaceae spp.}

We hypothesized that the net $\mathrm{N}$ release in the PS (Fig. 3) could be due to an increase in chitin-degrading microorganisms. In addition, the recorded plant growth promotion (Fig. 2) could be attributed to an increase in plant growthpromoting organisms nearby the plant roots. To investigate these hypotheses, we studied potential shifts in the potting soil and rhizosphere microbial community due to chitin treatment. In the time-course experiment, weekly BS and rhizosphere samples were taken to study the bacterial and fungal community by metabarcoding of the 16S rRNA and ITS 2 genes, respectively.

After filtering, a total of 3,209 bacterial amplicon sequence variants (ASVs) and 2,073 fungal ASVs were retrieved. A difference in bacterial community composition was noted between compartments (BS versus rhizosphere, permutational multivariate analysis of variance [PERMANOVA], $P<0.001$ ) and over time (PERMANOVA, $P<0.001$ ). In the rhizosphere, the proteobacteria decreased over time, whereas planctomycetes and verrucomicrobia increased (Supplementary Fig. S3). In BS however, the proteobacteria increased, whereas the numbers of acidobacteria and actinobacteria declined (Supplementary Fig. S3). The influence of chitin on the bacterial community composition was rather limited (Fig. 4A). When comparing $\mathrm{PS}+\mathrm{CH}$ with $\mathrm{PS}$, no shift in bacterial community composition was observed at the family level.

In contrast to the relatively stable bacterial community, chitin addition greatly influenced the fungal community of the rhizosphere (PERMANOVA, $P<0.001$ ) and the BS (PERMANOVA, $P<0.001$ ). A striking increase was noted in the Mortierellomycota phylum. One week after the start of the experiment, an increase from $0.5 \% \pm 0.2 \%$ to $74.8 \% \pm 6.8 \%$ was noted in the BS, with a quick decrease from week two onwards (Fig. 4B). In the rhizosphere, the increase in phylum Mortierellomycota is quite consistent over all plant developmental stages (Fig. 4B). All members of phylum Mortierellomycota could be attributed to family Mortierellaceae and genus Mortierella. In total, 22 high abundant $(>0.1 \%$ abundance in at least one sample) fungal ASVs were attributed to genus Mortierella. Several were highly abundant in both BS and the rhizosphere (ASVs 2, 6, 14, 29, 112, 9, 5), while others were only found in high abundance within the rhizosphere (ASVs 273, 43, 133, 198, 48), and this consistently over all points in time. Merely three of these ASVs were found in the pure chitin samples (ASVs 112, 9, 5) and, despite their high abundance within that sample, the count number is quite low $(15,24$, and 47, respectively) (Fig. 4C).
Next to family Mortierellaceae, abundance of a second fungal family was altered in $\mathrm{PS}+\mathrm{CH}$ over all plant developmental stages, namely, family Umbelopsidaceae. Only one fungal genus, Umbelopsis, was attributed to this family, for which one specific clade seemed to be majorly present when chitin was added to the medium. From week 5 of the experiment onwards, two additional fungal families increased significantly in chitinsupplemented substratem, families Pseudeurotiaceae and Entolomataceae, containing, respectively, members of four (Geomyces, Pseudeurotium, Pseudogymnoascus, and NA) and one (Clitopilus) fungal genera (Fig. 4D).

\section{Chitin induces resistance to $B$. cinerea in leaves but enhances susceptibility in fruit.}

To test the hypothesis that addition of chitin to the substrate would affect strawberry susceptibility to $B$. cinerea, infection assays were executed on leaves and on fruit.

Plant leaves were scored 7 and 9 days after inoculation (DAI) with $B$. cinerea. For each evaluation point, the overall infection rate (no lesion versus lesion) was significantly lower on plant leaves grown in PS+CH compared with PS (Fig. 5A). In addition, if infection occurred on the strawberry leaves grown in $\mathrm{PS}+\mathrm{CH}$, the lesion size was smaller compared with those grown in PS.

In contrast, for the strawberry fruit, an extreme significant increase in area under the disease progression curve (AUDPC) value ( $1 \mathrm{~m}, P<0.001)$ was observed when plants were grown in $\mathrm{PS}+\mathrm{CH}$ in the time-course experiment (Fig. 5B). A similar trend, although not significant, was seen in the fertilizer-dose experiment. Higher fertilizer doses led to a significantly higher AUDPC value $(\mathrm{lm}, P<0.05)$ and resulted in an additional increase due to the addition of chitin to the PS (Supplementary Fig. S4).

Observations from both experiments thus indicate that chitin addition results in a lower infection rate on the plant leaves and strawberry fruit become more susceptible to $B$. cinerea infection.

\section{Increased expression of defense genes in strawberry leaves} and priming effects upon chitin treatment.

The positive effects of chitin on disease resistance against Botrytis cinerea indicate an activation of the strawberry defense response in plant leaves. Therefore, gene expression was studied in plant leaves sampled 1 week after inoculation, when clear symptoms of infection were observed but necrosis would not influence results. Both inoculated (I) and mock-B. cinerea inoculated plants grown in PS or PS $+\mathrm{CH}$ were studied to evaluate potential priming of the foliar defense response. First, expression of six previously reported strawberry defenserelated genes was studied by RT-qPCR (Fig. 6A). PRI showed a significantly higher expression in leaves of chitin-treated plants, both in uninfected plants (PS+CH versus PS) and infected plants (PS+CH+I versus PS). Other defense genes are also induced in the $\mathrm{PS}+\mathrm{CH}+\mathrm{I}$ versus $\mathrm{PS}$ comparison but are only significant for FaWRKY1 (Fig. 6A).

Second, RNA sequencing was used to obtain a comprehensive overview of plant leaf gene expression. After filtering, $97.5 \% \pm 0.3 \%$ of the reads were retained. In total, $72.0 \% \pm$ $1.0 \%$ of these reads were mapped toward a reference database (Supplementary Table S8). Mere chitin addition (PS versus $\mathrm{PS}+\mathrm{CH}$ ) resulted in the upregulation of one gene, annotated as an auxin-induced protein (Hirakawa et al. 2014). Read counts of this gene were, however, low and very variable (PS, $1.3 \pm$ 1.5; PS $+\mathrm{CH}, 8.0 \pm 10.9$ ) questioning the biological relevance of this observation. Infection of plants with Botrytis cinerea (PS versus PS+I) resulted in an overall downregulation of host gene expression (86 downregulated, 46 upregulated, $P$ value 
$=0.0006313$ ). However, the effect of chitin amendment (PS versus $\mathrm{PS}+\mathrm{CH}+\mathrm{I})$ becomes apparent upon infection; 262 genes were upregulated and 219 were downregulated in chitinamended infected plants. When looking to the additive effect of chitin upon infection $(\mathrm{PS}+\mathrm{I}$ versus $\mathrm{PS}+\mathrm{CH}+\mathrm{I})$, a significant overall upregulation of gene expression is noted (55 upregulated genes to seven downregulated genes, $P$ value $=2.43 \mathrm{e}-10$ ), revealing a primed defense response to infection (Supplementary Table S9).

To study the biological relevance of these genes, gene ontology (GO) enrichment (using AgriGO and PLAZA), Kyoto Encyclopedia of Genes and Genomes (KEGG), and Mapman analyses were performed. AgriGO parametric analysis of gene set enrichment (PAGE) points to an upregulation in glutamate receptor activity (Fig. 6B). Focusing on the 'biological process' class of genes in the PLAZA GO enrichment analysis revealed enrichment of "stimulus"-related GO terms in the PS versus $\mathrm{PS}+\mathrm{I}$ and PS versus PS+CH+I treatments (Fig. 6C; Supplementary
Figs. S5 and S6). In addition, genes that are differentially expressed (DE) in the comparisons involving chitin amendment are enriched for the KEGG term "glycerolipid metabolism" (Fig. 6D). Especially transcription factors belonging to the MYB (myeloblastosis) family were significantly enriched in the PS versus PS+CH+I comparison, as well as the PS+I versus $\mathrm{PS}+\mathrm{CH}+\mathrm{I}$ comparison (Fig. 6E).

In general, we can thus conclude that addition of chitin leads to altered leaf gene expression, more specifically, the plant defense gene response, likely explaining lower leaf susceptibility.

\section{DISCUSSION}

Since strawberries are highly susceptible to diseases and their production comes with high nutrient costs, environmentally friendly alternatives for fertilization and plant protection are encouraged. We studied the applicability of chitin as an

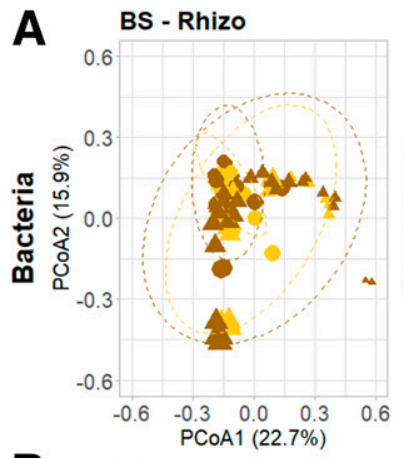

B
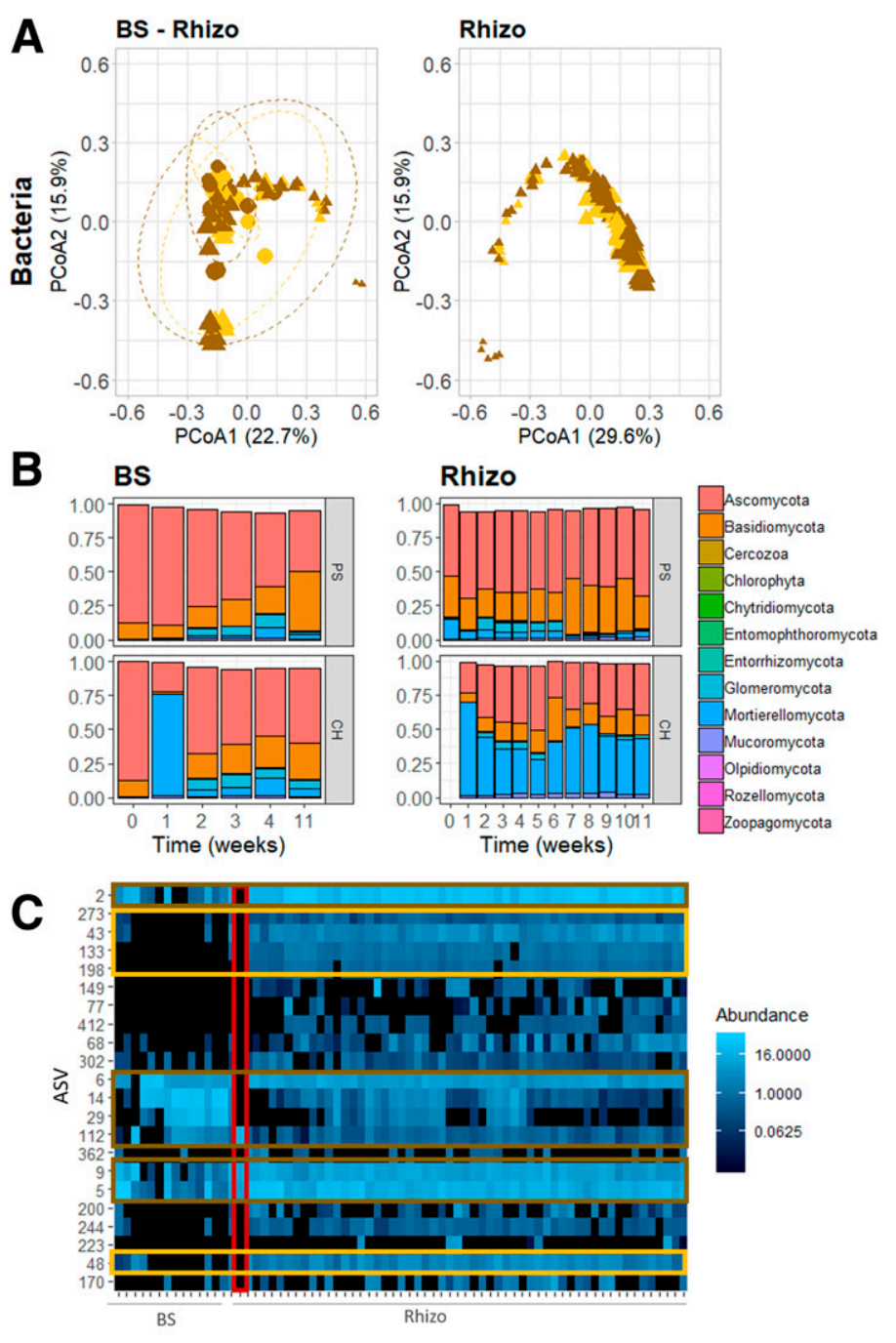
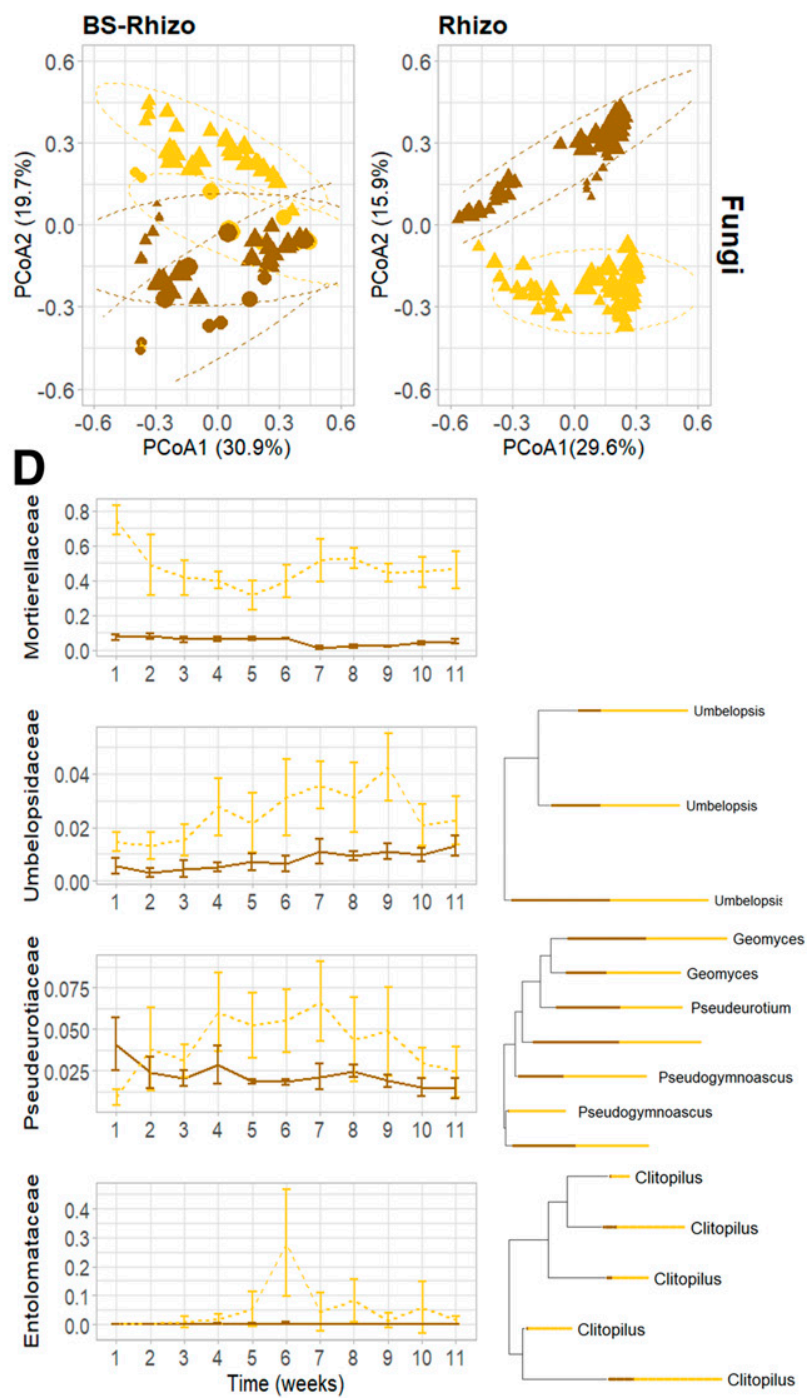

Fig. 4. Effect of chitin addition on the bacterial (the V3-V4 fragment of the 16S rRNA gene) and fungal (ITS2 gene) community of the bulk peat substrate (BS) and strawberry rhizosphere (rhizo) over time. A, PCoA plot showing that the bacterial community shifted over time; no effects of chitin addition could be observed (left), while, for the fungal community (right), an effect of chitin addition was present in both the BS and the rhizosphere. B, Fungal phyla and their change in time in the BS and rhizo. Especially the increase in Mortierellomycota due to chitin treatment can be noted. C, Fungal amplicon sequence variants (ASVs) with a count of at least 100 over all chitin-added samples. High abundances are indicated in blue. The Mortierella ASVs present in pure chitin flakes are indicated in red. Those highly abundant in both the BS and rhizo are indicated in brown, those only present in higher abundance in rhizo are indicated in yellow. D, Fungal families that are consistently differentially abundant due to chitin treatment for at least six successive weeks. For all plots, samples taken from peat substrate (PS) are indicated in brown, while chitin-amended PS is in yellow. 
amendment in strawberry cultivation. We presumed that i) chitin addition will increase strawberry growth and fruit production; ii) growth promotion is induced by higher nutrient availability in the growing media; iii) the nutrient release is mediated by a changed microbial community in the growing media; and iv) addition of chitin will trigger the plant defense response, resulting in reduced disease symptoms on strawberry leaves and fruit. Overall, we showed that chitin addition results in an increase in plant shoot weight and chlorophyll content, decreases in root weight, and fewer and smaller fruits. These changes are related to a higher $\mathrm{N}$ concentration in the growing medium resulting in a higher $\mathrm{N}$ uptake by the plant and fruit. Chitin did not change the bacterial community but caused an increase of the Mortierella fungi in the BS and, especially, in the plant rhizosphere. Finally, chitin addition makes fruit more susceptible to $B$. cinerea but reduces infection rates on plant leaves, correlated with a higher foliar defense gene expression.

In accordance with previous research on lettuce (Debode et al. 2016), application of chitin to substrate increased the plant shoot biomass. As expected, total $\mathrm{N}$ concentration in the substrate increased, probably by an active degradation of chitin by chitinase-producing microorganisms (De Tender et al. 2019; Winkler et al. 2017). In acid soils, chitin degradation is often dominated by fungi (De Boer et al. 1999). Despite the observation that the addition of chitin significantly increased the PS $\mathrm{pH}$ during the first weeks of plant growth, the substrate remained rather acid later on in the trial $(\mathrm{pH}<5)$. Indeed, both in the BS and the rhizosphere, changes were only noted in the fungal community, with an enormous increase in relative abundance of the fast-growing, chitinolytic fungi of the genus Mortierella (Kim et al. 2008).

The increased $\mathrm{N}$ release is also reflected in the plant shoots and fruit, for which higher $\mathrm{N}$ concentrations were noted. Chitinmediated growth promotion can thus be related to higher nutrient concentrations in the growing medium. Yet, increased fertilization still resulted in an additional benefit of chitin on plant growth, indicating that other mechanisms might be involved as well. Previous research showed that low-molecular weight forms of chitin act as bio-stimulators of plant growth by an activation of genes related to plant development (Winkler et al. 2017). This hypothesis is not confirmed in our study, as RNA-seq of plant leaves continuously grown in chitin-enriched substrate only showed upregulation of one gene. On the other hand, plants actively produce and secrete metabolites to shape and tailor the microbial community around their roots, in function of their growth and development (Huang et al. 2019). The occurrence of rhizosphere-specific Morteriella ASVs and the quick decline of Mortierella abundance in the BS point to an active attraction of Morteriella species toward the rhizosphere. In addition, high abundances of ASVs classified as genera Umbelopsis and Clitopilus were observed in the plant rhizosphere grown in chitin-enriched PS. Both Mortierella and Umbelopsis genera contain species previously indicated to improve plant growth (Johnson et al. 2019; Li et al. 2017; Özkale 2019).

In contrast to the shoot biomass, strawberry fruit production was negatively influenced by chitin addition. Fruits were smaller and the overall yield was lower. Foliar analyses of the fertilizer-dose experiment indicated that $\mathrm{N}, \mathrm{P}$, and $\mathrm{K}$ were all limiting elements for plant growth. Higher doses of PGMix mineral fertilizer resulted in similar foliar concentrations but higher plant biomass. In contrast to PGMix, chitin only served as a source of mineral $\mathrm{N}$, while reducing the total uptake of $\mathrm{P}$ in leaves and fruit, resulting in a $\mathrm{P}$ and $\mathrm{K}$ imbalance for strawberry production. We propose that these deficiencies can be explained by i) $\mathrm{pH}$ effect, ii) $\mathrm{P}$ fixation by chitin, iii) high nutrient uses for microbial growth, as chitin can lead to a doubling of the microbial biomass in the substrate (Debode et al. 2016), and iv) a shift in energy balance toward plant defense, limiting nutrient availability for root growth and fruit development. To investigate these hypotheses, additional studies are necessary.

Chitin is generally known as a PAMP, and thus, beneficial effects on disease resistance of plant fruit and shoots toward $B$. cinerea were expected. Whereas a positive effect in disease resistance was noted on the strawberry leaves, symptoms of gray mold infection appeared quicker on fruits obtained from plants grown in $\mathrm{PS}+\mathrm{CH}$. This could be due to a disruption of the defense-growth balance; an excessive $\mathrm{N}$ supply and imbalance with other chemical nutrients could result in higher susceptibility of strawberry to plant pathogens (Nam et al. 2006; Xu et al. 2013).

Whereas Botrytis infection led to a general suppression of gene expression in plants grown in unamended substrate, in chitin-amended substrate infection resulted in the activation of several defense-related genes. An initial analysis with RT-qPCR indicated an enhanced expression of FaPRl in chitinamended plants. PR1 specifically is thought to have antimicrobial properties through sterol binding and the amplification of defense signals (Gamir et al. 2017). FaWRKY1 was only
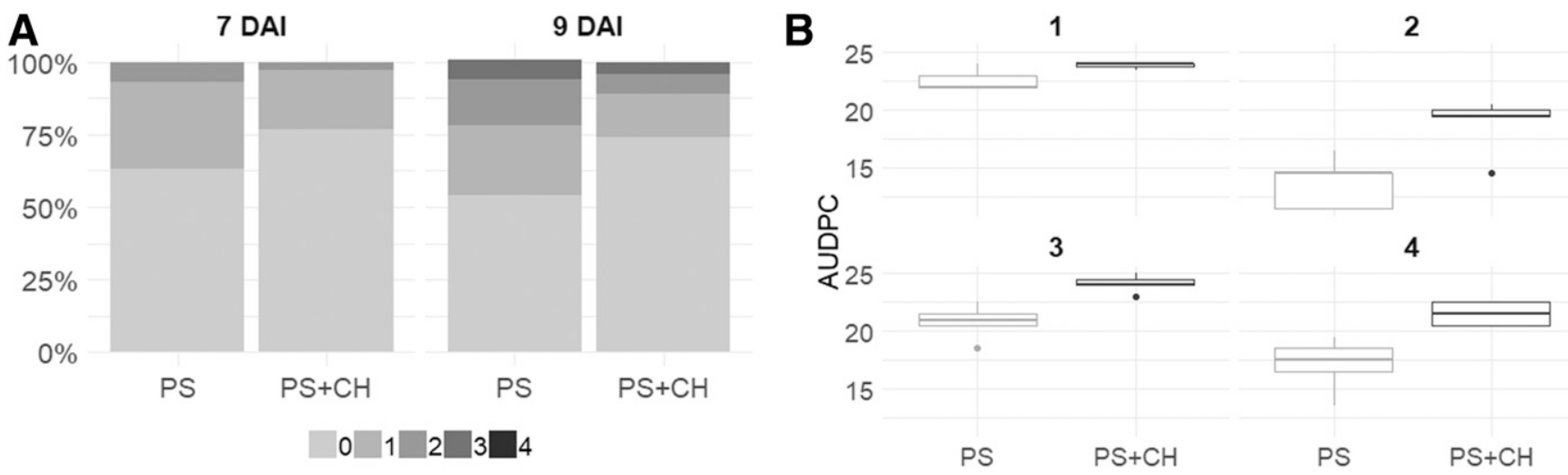

Fig. 5. Scoring Botrytis cinerea infection on strawberry plant leaves and fruit. Strawberry plant leaves were inoculated at 8 weeks of plant growth. In total, three fully expanded leaves per plant were inoculated and, per condition (peat substrate [PS]) or chitin-amended PS [PS+CH]), 12 plants were inoculated. The disease was scored with a value of 0 (no infection) to 4 (100\% infected leaf) 7, 9, and 12 days after inoculation (DAI). A, the score abundances over all plants and leaves are visualized. B, In addition, strawberry fruits $(n=6$ per timepoint per tray) were inoculated with $B$. cinerea after picking. Fruits were discarded once infection symptoms were observed and the area under the disease progression curve (AUDPC) was calculated based on this measurement and was visualized per treatment. The AUDPC value per tray $(n=5)$ is represented in a boxplot. 


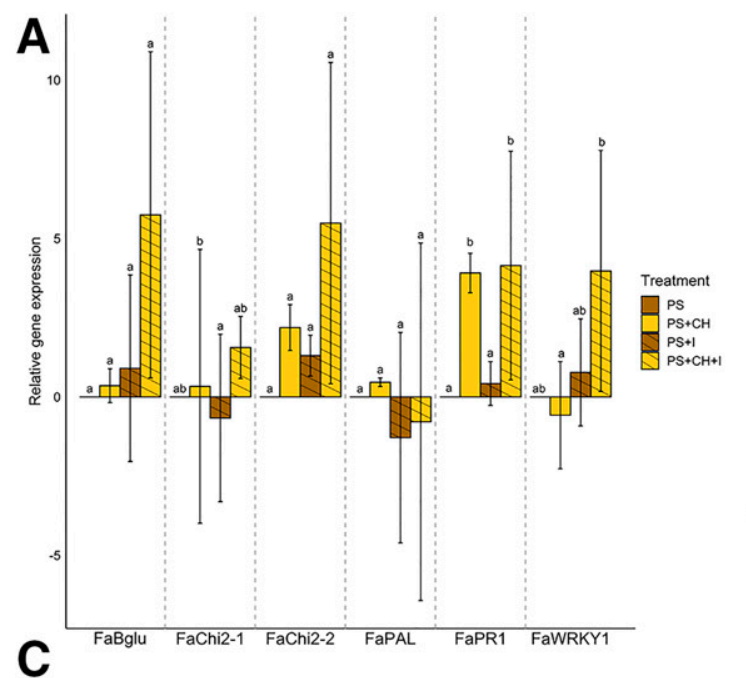

B
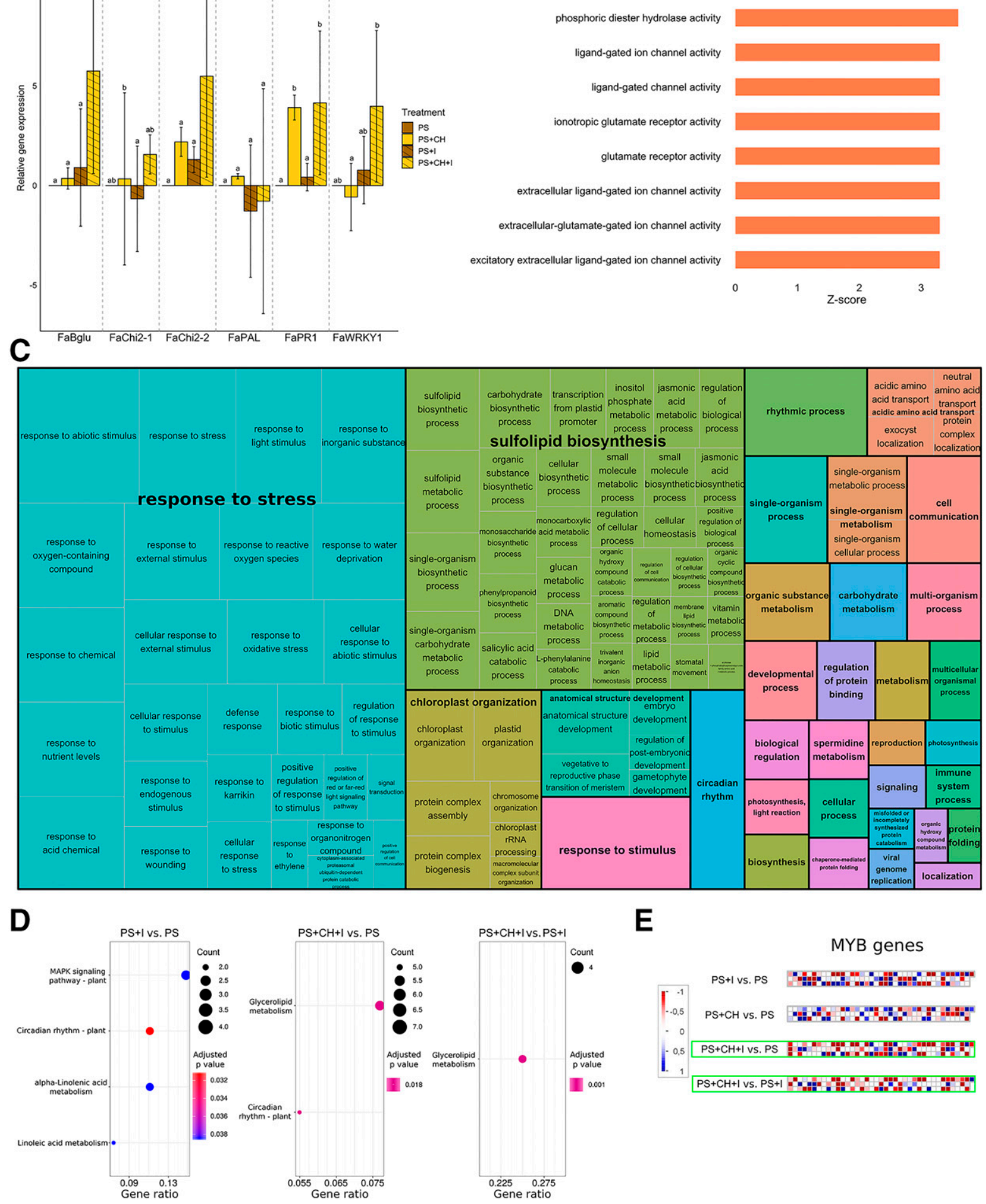

$\mathbf{E}$

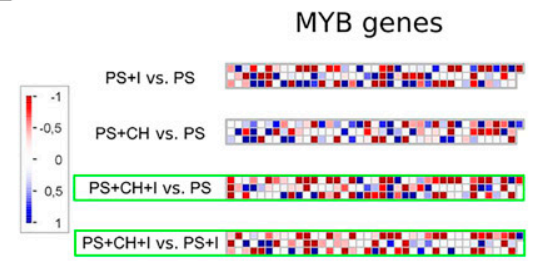

Fig. 6. Gene expression in strawberry leaves. A, Relative gene expression values (by reverse transcription quantitative PCR) of six defense genes in strawberry for peat substrate (PS) and chitin treatments $(\mathrm{PS}+\mathrm{CH})$, inoculated with Botrytis cinerea (I) or mock-inoculated. Expression values are expressed in $\log _{2}$ fold (LFC) changes. The PS treatment is used as control treatment; for this treatment, the expression value is set to 0. Statistically significant differences are indicated with different letters. B, AgriGO parametric analysis of gene set enrichment analysis. C, Gene ontology (GO) enrichment analysis (Biological process) of genes differentially expressed in PS versus PS+CH+I comparison. The size of the boxes corresponds with the significance of the GO terms. D, Kyoto Encyclopedia of Genes and Genomes (KEGG) gene set enrichment analysis. Each figure shows the significantly enriched KEGG terms per comparison. Gene ratio is the ratio of genes that are associated with a particular KEGG term versus the total number of genes with any KEGG annotation. Count denotes the number of genes with a particular KEGG term. Adjusted $P$ value denotes the significance of the enrichment. E, Mapman analysis of MYB genes. The red-toblue coloring indicates the LFC change levels of the MYB genes. The green frame indicates the comparisons in which a significant enrichment for MYB genes was found. 
activated strongly upon inoculation in chitin-supplemented plants, indicating a primed defense response. A more detailed RNA-seq analysis revealed that genes involved in linoleic acid metabolism and alpha-linolenic acid metabolism, a precursor for jasmonic acid (JA) in the octadecanoid synthesis pathway (Ruan et al. 2019), as well as mitogen-activated protein kinases (MAPKs) were strongly upregulated in chitin-supplemented infected plants. MAPKs are well-described in regard to their involvement in the transduction of environmental and developmental signals and induced resistance (Taj et al. 2010) and play a role in a variety of plant-pathogen interactions such as Pseudomonas syringae pv. tomato and Arabidopsis thaliana and B. cinerea in Nicotiana benthamiana (Adachi et al. 2016; $X i n$ et al. 2009). Infection of strawberry plants grown in chitinenriched substrate showed a defense priming effect, which might explain the lower disease incidence of the plant leaves. Genes that are differentially enriched in the leaves of chitintreated plants are attributed to stress-related GO terms as well as GO and KEGG terms related to lipid metabolism. Plants are able to alter their membrane composition in response to plant stress, as lipids do not only function as structural building blocks but, also, as signaling and precursor molecules (Lavell and Benning 2019; Walley et al. 2013). Polyunsaturated fatty acids are released from membranes by lipases in response to biotic stress. In avocado fruit, for example, elevated levels of 18:2-type fatty acids confer enhanced resistance against the fungal pathogen Colletotrichum gloeosporioides (Madi et al. 2003). Changes in glycerolipid metabolism also interlink with the aforementioned observations regarding JA biosynthesis. Membrane lipids can be metabolized to alpha-linolenic acid, which is eventually converted to JA (Chehab et al. 2008). An enrichment for MYB genes in the PS versus $\mathrm{PS}+\mathrm{CH}+\mathrm{I}$ and the $\mathrm{PS}+\mathrm{I}$ versus $\mathrm{PS}+\mathrm{CH}+\mathrm{I}$ comparison was noted, revealing that expression of these genes is directly affected in chitin-amended strawberry plants, regardless of infection. They code for a class of transcription factors that are implicated in a range of plant processes, such as cold stress tolerance, drought and salt tolerance, and biotic stress (Ambawat et al. 2013; Liu et al. 2010; Seo and Park 2010). Some MYB genes are transcriptionally regulated by JA (Hickman et al. 2017; Lee et al. 2001). Strong induction of JA responses is typically associated with negative effects on root growth, as also observed in the current study (Huang et al. 2017). An excessive defense response activated in the foliar tissues could negatively affect the growth-defense balance in strawberry plants and, hence, contribute to the observed negative effects on root growth, fruit development, and fruit susceptibility.

To conclude, chitin application may be effective to reduce the dose of mineral fertilizers and plant protection products in strawberry cultivation as growth promotion of the green plant parts and defense priming were observed. As chitin almost exclusively releases $\mathrm{N}$ into the growing media, a good fertilization strategy with higher doses of $\mathrm{P}$ and $\mathrm{K}$ is required to avoid nutrient imbalances and a too-strong defense reaction and, thus, negative results on fruit yield, root growth, and disease resistance.

\section{MATERIALS AND METHODS}

In the time-course experiment, temporal variation was monitored by characterizing the growing media, plant leaves, and fruit chemically, by measuring the plant and fruit development, and evaluating changes in the bacterial and fungal community weekly for plants grown in PS and PS+CH. Half of the plants and fruit were infected with Botrytis cinerea after 8 weeks of growth, to evaluate disease incidence and measure defense gene expression by RT-qPCR and RNA sequencing (Fig. 1).
In the fertilizer-dose experiment, the effect of chitin on plant growth and fruit development, as well as PS chemical composition was evaluated in combination with increasing mineral fertilization (Fig. 1).

\section{Experimental design.}

Strawberry plants (F. ananassa cultivar Elsanta) were grown in 1.5-liter pots containing Novobalt white peat $100 \%$ (AVEVE Lammens, Wetteren, Belgium), mixed with, per liter, $0.35 \mathrm{~g}$ of Ecomix organic fertilizer, $1.43 \mathrm{~g}$ of lime (RHP MG'sGravenzande, South Holland, The Netherlands), and $0.35 \mathrm{~g}$ of Haifa Multimix potting soil 14+16+18 (+micronutrients) PGMix fertilizer (Haifa North West Europe, Mechelen, Belgium). In the fertilizer-dose experiment, three different fertilization dosages were used: no PGMix (low dose), $0.35 \mathrm{~g}$ of fertilizer per liter $(1 \times$ PGMix, medium dose $)$, and $1.05 \mathrm{~g}$ of fertilizer per liter $(3 \times$ PGMix, high dose). Half of the PS mixtures was used as such (PS), while the other half was mixed with $2 \mathrm{~g}$ of DM chitin per liter of PS (PS+CH). All mixtures were wetted to obtain $40 \%$ water-filled pore space (WFPS) and were put in a closed bag to preincubate at $15^{\circ} \mathrm{C}$ for 1 week. No additional fertilizer was applied during plant growth. Every week, the moisture content of the substrate was adjusted to $40 \%$ WFPS based on mass loss. The water volume added per pot was recorded until 7 weeks of plant growth (Supplementary Table S10). From week 8 onwards, this became impossible, as high humidity was required for the $B$. cinerea bioassay.

In the time-course experiment, cold-stored bare-root strawberry (Fragaria $\times$ ananassa, cultivar Elsanta) transplants were planted in half of the pots, the other half contained mere BS. Pots with and without plants were arranged in the greenhouse in a semi-randomized design (Supplementary Fig. S7) and were grown at $20^{\circ} \mathrm{C}$ for 11 weeks. In total, six biological replicates were sampled weekly per timepoint $\times$ growing medium combination. At week 8 of plant growth, the $B$. cinerea bioassay was done on the plant leaves of the remaining plants.

In the fertilizer-dose experiment, cold-stored bare-root strawberry transplants (Fragaria $\times$ ananassa, cultivar Elsanta) were planted in all pots. The pots were arranged in a semirandomized design in the greenhouse and plants were grown for 11 weeks at $20^{\circ} \mathrm{C}$ (Supplementary Fig. S8). In total, ten biological replicates per growing medium $\times$ fertilizer dose combination were sampled at the end of the experiment.

\section{Measurement of plant physiological parameters.}

Strawberry plants were sampled weekly (time-course experiment) or after 11 weeks of plant growth (fertilizer-dose experiment) and were weighed ( $\mathrm{FW}$ and DW at $48 \mathrm{~h}$ at $\left.70^{\circ} \mathrm{C}\right)$. In addition, the root system was rinsed with sterilized water and weighed.

In the time-course experiment, the leaf chlorophyll content was estimated weekly as described in detail by Debode et al. (2018).

From week 6 onwards, fruit started to appear on the plants. Ripe fruit was picked per plant for all plants remaining in the greenhouse and was counted and weighed $(\mathrm{FW})$ at four points in time (week 6 until week 9). Some of these fruits were inoculated with $B$. cinerea (discussed below). The remaining fruits were used for chemical characterization, and this for both experiments.

\section{Chemical characterization of the growing media.}

The chitin flakes, purified from crab shells, were obtained from BioLog Hepp Gmbh and were chemically analyzed as published by De Tender et al. (2019) (Supplementary Table S2).

The PS was sampled weekly for 11 weeks (discussed above) for the time-course experiment and at the beginning and end of 
the fertilizer-dose experiment. In total, three biological replicates per condition were studied. According to EN 13040, DM content was determined. Electrical conductivity (EN 13038) and $\mathrm{pH}-\mathrm{H}_{2} \mathrm{O}(\mathrm{EN} 13037)$ were measured in a 1:5 soil to water ( $\mathrm{vol} / \mathrm{vol}$ ) suspension. Water-extractable $\mathrm{PO}_{4}-\mathrm{P}, \mathrm{NO}_{3}-\mathrm{N}, \mathrm{Cl}$, $\mathrm{SO}_{4}, \mathrm{NH}_{4}-\mathrm{N}, \mathrm{C}, \mathrm{Cu}, \mathrm{Si}, \mathrm{K}, \mathrm{Ca}, \mathrm{Mg}$, and $\mathrm{Na}$ concentrations were measured as described by De Tender et al. (2019).

\section{Chemical characterization of plant leaves and strawberry fruit.}

Plant leaves were chemically analyzed on weeks 3,6 , and 9 of the time-course experiment and at week 11 for the fertilizerdose experiment. In total, three biological replicates were studied per timepoint $\times$ mixture $(\mathrm{PS}, \mathrm{PS}+\mathrm{CH})$. Leaves were dried at $70^{\circ} \mathrm{C}$ and were ground, and the material of three plants was mixed and considered as one biological replicate. Fruits were freeze-dried before grinding. Total $\mathrm{N}$ was determined by Thermo Scientific Flash $4000 \mathrm{~N}$ analyzer, total concentrations of $\mathrm{P}, \mathrm{K}, \mathrm{Mg}$, and $\mathrm{Ca}$ were determined by $5110 \mathrm{VDV}$ Agilent ICP-OES in the extract, based on adding $10 \mathrm{ml}$ of $\mathrm{HCl}(1 \mathrm{~N})$ to the ash after incineration of $0.5 \mathrm{~g}$ for a minimum $6 \mathrm{~h}$ at $450^{\circ} \mathrm{C}$. Assessment of optimal range and nutrient deficiency for foliar composition is based on Pritts et al. (2015). Total uptake in the leaves and fruit was calculated by multiplying the measured concentration with the dry mass of leaves and fruit.

\section{Microbial analysis.}

Analysis of the bacterial and fungal microbial community was done in the time-course experiment. Weekly, six biological replicates were taken from the strawberry rhizosphere (pots with plants), according to Lundberg et al. (2012), and the BS (pots with no plants) by sampling $250 \mathrm{mg}$ of medium per pot. In addition, $250 \mathrm{mg}$ of pure chitin was used for metabarcoding analysis. DNA of the samples was extracted with the DNeasy powersoil kit (Qiagen, Hilden, Germany), according to manufacturer instructions, and was stored at $-20^{\circ} \mathrm{C}$ before use.

Metabarcoding of the bacterial and fungal rhizosphere was done on the V3-V4 fragment of the 16S rRNA gene and the ITS2 gene fragment, respectively (Illumina, San Diego, CA, USA). Library preparation, quality control, and pooling was done as described by De Tender et al. (2016a). Resulting libraries were sequenced using Illumina MiSeq v3 technology ( $2 \times 300$ bp), by Admera (South Plainfield, NJ, U.S.A.), spiked with $30 \%$ PhiX DNA.

Demultiplexing of the raw sequencing reads was done by the sequencing provider. Reads are available for download at the National Center for Biotechnology Information (NCBI) sequence read archive under project numbers PRJNA576171 and PRJNA576339 for the bacterial and fungal sequences, respectively.

Trimming, filtering, merging of the reads, dereplication, sorting, ASV calling, and chimera removal was done making use of the DADA2 algorithm v1.10 (Callahan et al. 2016). Briefly, all ambiguous bases were removed and the number of maximum expected errors for forward and reverse reads should not exceed three. Based on the quality profiles of the forward and reverse reads, the truncation length was set on 263 and $240 \mathrm{bp}$, respectively. A parametric error model was built for the forward and reverse read separately, for which convergence was reached after nine and six rounds. After dereplication (removal of duplicate reads), reads were merged and an ASV table was built. To assign taxonomy through the decipher library (v2.12.0) to the resulting ASVs, the SILVA database v132 (Quast et al. 2013), for the V3-V4 16S rRNA gene sequences, and the UNITE database v7.1 (Kõljalg et al. 2013), for the ITS2 sequences, were used as references. The resulting count table was used for statistical analysis.

\section{Botrytis cinerea bioassay.}

For the time-course experiment, plant leaves of half of the plants were inoculated after 8 weeks of plant growth with B. cinerea (strain PCF895 [Debode et al. 2013]) according to the method of Meller Harel et al. (2012) and described in detail by De Tender et al. (2016a). The other half of the plants were inoculated with sterile potato dextrose agar plugs. The resulting lesions on the leaflets were recorded 1 week after inoculation, using a 0 to 4 disease scale (Supplementary Fig. S9). This scoring was used to calculate the disease severity index (DSI) per plant $(i)$ used as input for statistical analysis.

$$
D S I_{i}=100 \times \frac{1 \times n_{i 1}+2 \times n_{i 2}+3 x n_{i 3}+4 x n_{i 4}}{4 \times n_{i}}
$$

Where $n_{i} 1, \ldots, n_{i} 4$ represent the number of leaves of each infection score and

$$
n_{i}=\sum_{l=0}^{4} n_{i l}=9
$$

is the number of leaves measured for each plant. This index has values in the interval $[0,100]$, with a minimum index if all leaves score 0 and a maximum when all leaves score 4 . Inoculated leaves remained on the plant until the end of the experiment.

From the moment fully ripened strawberry fruits were formed, these were picked and ten fruits per treatment were inoculated with $B$. cinerea, according to the method of Bhaskara Reddy et al. (2000) and described in detail by De Tender et al. (2016a). The AUDPC was calculated based on the disease scores (Campbell and Madden 1990; Schandry 2017). In total, the inoculation was repeated independently four times for both experiments.

\section{RNA extraction and gene expression analysis.}

In the time-course experiment, six plugs $(0.5 \mathrm{~cm})$ of plant leaves were collected per plant, were pooled and flashfrozen in liquid nitrogen, and were stored at $-80^{\circ} \mathrm{C}$ until use. Samples were taken from plant leaves 1 week after inoculation, both from inoculated and non-inoculated plants. To avoid too much necrosis (Windram et al. (2012), leaves with an infection score of 1 were taken for plants inoculated with $B$. cinerea.

Gene expression was analyzed on leaves from strawberry plants i) grown in PS, mock-inoculated (PS), i) grown in chitinenriched PS, mock-inoculated $(\mathrm{PS}+\mathrm{CH})$, iii) grown in PS and B. cinerea inoculated (PS+I), or iv) grown in chitin-enriched PS and $B$. cinerea inoculated ( $\mathrm{PS}+\mathrm{CH}+\mathrm{I})$. For each sample type, three biological replicates were taken. RNA was extracted from the plant leaves according to Luypaert et al. (2017) and were described in detail by Debode et al. (2018). DNase treatment was done using the DNA-free kit (Ambion, Thermo-Fisher Scientific, Sugarland, TX, U.S.A.). For cDNA synthesis, the Tetro cDNA synthesis kit (Bioline, Camarillo, CA, U.S.A.) was used, starting from $1.5 \mu \mathrm{g}$ of DNA-free RNA.

First, gene expression was studied by RT-qPCR on nine genes (three reference genes and six defense-related genes [Supplementary Table S11]), as described in detail by Debode et al. (2018). We used SYBR green as implemented in the Sensimix-SYBR-no-ROX-kit of GC biotech for RT-qPCR.

Second, to obtain a comprehensive overview, RNA sequencing was used to study overall gene expression of the plant leaves. Construction of libraries and sequencing was done by nxtgnt (Ghent, Belgium). Samples were enriched in mRNA by targeting the 3' polyA-tail using poly-T oligos attached to magnetic beads. The enriched mRNA was converted into cDNA. Samples were multiplexed by using unique barcodes (Kukurba and Montgomery 2015) and were pooled. 
Sequencing of the library was done using the Illumina HiSeq 3000 platform $2 \times 150$ bp (Gene Expression Omnibus data accession number GSE144526) . Demultiplexing was done by the sequencing provider. Read quality was evaluated with FastQC v0.11.8 (Andrews 2010), by which adapters and lowquality sequences were removed, using Trimmomatic v0.38 (Bolger et al. 2014). Reads were truncated if the mean quality score dropped below 20 in a window of 5 bases. Remaining reads with a length smaller than 20 bases were removed. The resulting reads were mapped to the $F$. ananassa reference genome (Hirakawa et al. 2014) with STAR v2.6.1d (Dobin et al. 2013). Based on the resulting alignment files, a count table was built using $\mathrm{R}$ package GenomicAlignments (Lawrence et al. 2013). Only uniquely mapping reads were taken into account. This count table was further used for differential expression analysis with edgeR.

RNA sequencing results were analyzed using i) GO enrichment, ii) KEGG, and iii) Mapman (v3.6.0RC1 [Thimm et al. 2004]) analysis. Each of these tools works with a distinct set of gene IDs based on different $F$. vesca annotations. To convert the gene IDs of the $F$. ananassa reference genome, three annotations and corresponding gene sequences were retrieved for $F$. vesca, namely, the $F$. vesca v1.1 assembly from Phytozome (version 10 [Goodstein et al. 2012]) for GO analysis, the NCBI assembly of $F$. vesca 1.0 for KEGG analysis. and the Phytozome (version 9) $F$. vesca v1.0 assembly for Mapman analysis. For each annotation, corresponding gene sequences were used to create a BLAST database using a locally installed version of the NCBI BLAST service (v2.9.0+) (Tao 2008). The database was subsequently masked using the dustmasker algorithm. Gene sequences of $F$. ananassa were blasted against each of these databases. For KEGG analysis, only DE genes were used for BLAST annotation. For Mapman analysis, all $F$. ananassa gene sequences were used for BLAST annotation, with an evalue cut-off of 10-5. GO enrichment analysis was executed for DE genes using the PLAZA 4.0 for dicots (Van Bel et al. 2018). GO visualization was done using REVIGO (Supek et al. 2011). AgriGO was used for the PAGE, using the logtwofold change (LFC) values of all genes. Benjamini and Hochberg false discovery rate correction was performed, using the default parameters, to adjust the $P$ value. KEGG analysis was performed using the $\mathrm{R}$ package clusterProfiler ( $\mathrm{Yu}$ et al. 2012). For Mapman analysis, gene IDs were combined with the corresponding LFC values calculated by edgeR. Wilcoxon rank sum tests were used to determine significantly enriched pathways, with Benjamini-Hochberg correction for multiple testing. Two sided binomial tests were used to determine significant tendencies toward up- or downregulation.

\section{Statistical analysis.}

Statistical analysis of the PS, plant leaves, and plant fruit chemical concentrations was done using a general linear model $(\mathrm{lm})$ in which chitin treatment and time were set as two factors within the time-course experiment, and chitin treatment and fertilizer dose were set as factors in the fertilizer-dose experiment. To obtain data normality, the concentration of nutrients was log-transformed. Homogeneity of variances was checked by means of boxplots.

The temporal evolution of the plant FW, DW, root weight, and chlorophyll content was expected to be nonlinear. Therefore, a generalized additive model was used to analyze these response variables, making use of a Loess smoother.

$$
y_{i}=f_{a}\left(t_{i}\right)+x_{i} f_{b}\left(t_{i}\right)+\varepsilon_{i}
$$

Herein, $y_{i}$ is the plant $\mathrm{FW}$, DW, root weight, or chlorophyll content of observation $i, t_{i}$ the time in weeks at which observation $i$ is taken, $f_{a}\left(t_{i}\right)$ a smoother to model the evolution of the average of the response variable, and $x_{i}$ an indicator variable, which is $x_{i}=0.5$ when chitin was added to the PS, and $x_{i}=-0.5$ when plants were grown in mere PS.

Within the time-course experiment, differences in the bacterial or fungal total community were studied in which chitin treatment and time were indicated as the main factors in the experiment. ASV tables were first filtered to remove low abundant counts. ASVs with a count of two in at least six samples were kept for analysis. The multivariate analysis was done using the $\mathrm{R}$ package vegan (version 2.5.4) (Oksanen et al. 2010). A dissimilarity matrix was built, based on the BrayCurtis dissimilarity index, from the ASV table as generated by DADA2, for both bacterial and fungal sequences. Homogeneity of variances was checked on this dissimilarity matrix by the betadisper function. Further, the significance of chitin treatment, time, and the interaction effect between chitin treatment and time were analyzed using PERMANOVA analysis in which the Bray-Curtis dissimilarity matrix was used as an input. In addition, differential abundances were assessed using likelihood-ratio tests, for which we tested the effect of treatment within each timepoint. The analyses were done upon clustering the bacterial and fungal ASV tables at family level. These analyses were done using an edgeR package, version 3.24.3 (Robinson et al. 2010), and were described in more detail by De Tender et al. (2016b).

For plant leaf infection, the DSI was used as response variable for disease score. A linear mixed effect model was fitted with DAI ( 7 and 9 days) and chitin treatment as fixed main effects and the plant as random effect. For $B$. cinerea infection on fruit, the AUDPC value is used as disease index. A generalized linear model was used with chitin treatment and repeat (infection was scored on four independent timepoints) as main effects, according to Schandry (2017).

To analyze changes in gene expression of the RT-qPCR data, the relative quantitation technique was used and described in detail by Debode et al. (2018). Statistical significance of the differential expression levels was analyzed using a linear model by which chitin treatment and $B$. cinerea infection were set as main effects and the interaction treatment $\times$ infection was taken into account.

DE genes were analyzed using edgeR version 3.4 .3 for the RNA sequencing data. After trimmed mean of $M$ value normalization, a negative binomial model with main effects for treatment and infection as well as treatment $\times$ infection interaction was used. Significant DE genes were obtained by likelihood ratio tests on the appropriate contrasts.

\section{ACKNOWLEDGMENTS}

We want to thank P. Quataert for advice on the statistical analysis.

\section{LITERATURE CITED}

Adachi, H., Ishihama, N., Nakano, T., Yoshioka, M., and Yoshioka, H. 2016. Nicotiana benthamiana MAPK-WRKY pathway confers resistance to a necrotrophic pathogen Botrytis cinerea. Plant Signal. Behav. 11:e1183085.

Ait Barka, E., Eullaffroy, P., Clément, C., and Vernet, G. 2004. Chitosan improves development, and protects Vitis vinifera L. against Botrytis cinerea. Plant Cell Rep. 22:608-614.

Algam, S. A. E., Xie, G., Li, B., Yu, S., Su, T., and Larsen, J. 2010. Effects of Paenibacillus strains and chitosan on plant growth promotion and control of Ralstonia wilt in tomato. J. Plant Pathol. 92:593-600.

Ambawat, S., Sharma, P., Yadav, N. R., and Yadav, R. C. 2013. MYB transcription factor genes as regulators for plant responses: An overview. Physiol. Mol. Biol. Plants 19:307-321.

Andrews, S. 2010. FastQC: A quality control tool for high throughput sequence data. Accessed March 10, 2019. Brabraham Institute, 
Cambridge. Published online. at:http://www.bioinformatics.babraham.ac.uk/ projects/fastqc

Basosi, R., Spinelli, D., Fierro, A., and Jez, S. 2014. Mineral nitrogen fertilizers: Environmental impact of production and use. Pages 1-42 in: Fertilizers: Components, Uses in Agriculture and Environmental Impacts. F. Lòpez-Valdez, and F. Fernàndez Luqueno, eds., NOVA Science Publishers, Hauppauge, NY, U.S.A.

Bhaskara Reddy, M. V., Belkacemi, K., Corcuff, R., Castaigne, F., and Arul, J. 2000. Effect of pre-harvest chitosan sprays on post-harvest infection by Botrytis cinerea and quality of strawberry fruit. Postharvest Biol. Technol. 20:39-51.

Bolger, A. M., Lohse, M., and Usadel, B. 2014. Trimmomatic: A flexible trimmer for Illumina sequence data. Bioinformatics 30:2114-2120.

Callahan, B. J., McMurdie, P. J., Rosen, M. J., Han, A. W., Johnson, A. J., and Holmes, S. P. 2016. DADA2: High-resolution sample inference from Illumina amplicon data. Nat. Methods 13:581-583.

Campbell, C. L., and Madden, L. V. 1990. Introduction to plant disease epidemiology. John Wiley \& Sons, New York.

Chehab, E. W., Kaspi, R., Savchenko, T., Rowe, H., Negre-Zakharov, F., Kliebenstein, D., and Dehesh, K. 2008. Distinct roles of jasmonates and aldehydes in plant-defense responses. PLoS One 3:e1904.

De Boer, W., Gerards, S., Klein Gunnewiek, P. J. A., and Modderman, R 1999. Response of the chitinolytic microbial community to chitin amendments of dune soils. Biol. Fertil. Soils 29:170-177.

De Tender, C., Haegeman, A., Vandecasteele, B., Clement, L., Cremelie, P., Dawyndt, P., Maes, M., and Debode, J. 2016b. Dynamics in the strawberry rhizosphere microbiome in response to biochar and Botrytis cinerea leaf infection. Front. Microbiol. 7:2062.

De Tender, C., Mesuere, B., Van der Jeugt, F., Haegeman, A., Ruttink, T., Vandecasteele, B., Dawyndt, P., Debode, J., and Kuramae, E. E. 2019. Peat substrate amended with chitin modulates the N-cycle, siderophore and chitinase responses in the lettuce rhizobiome. Sci. Rep. 9:9890.

De Tender, C. A., Debode, J., Vandecasteele, B., D'Hose, T., Cremelie, P., Haegeman, A., Ruttink, T., Dawyndt, P., and Maes, M. 2016a. Biological, physicochemical and plant health responses in lettuce and strawberry in soil or peat amended with biochar. Appl. Soil Ecol. 107: $1-12$.

Dean, R., Van Kan, J. A., Pretorius, Z. A., Hammond-Kosack, K. E., Di Pietro, A., Spanu, P. D., Rudd, J. J., Dickman, M., Kahmann, R., Ellis, J., and Foster, G. D. 2012. The top 10 fungal pathogens in molecular plant pathology. Mol. Plant Pathol. 13:414-430.

Debode, J., De Tender, C., Cremelie, P., Lee, A. S., Kyndt, T., Muylle, H., De Swaef, T., and Vandecasteele, B. 2018. Trichoderma-inoculated miscanthus straw can replace peat in strawberry cultivation, with beneficial effects on disease control. Front. Plant Sci. 9:213.

Debode, J., De Tender, C., Soltaninejad, S., Van Malderghem, C. Haegeman, A., Van der Linden, I., Cottyn, B., Heyndrickx, M., and Maes, M. 2016. Chitin mixed in potting soil alters lettuce growth, the survival of zoonotic bacteria on the leaves and associated rhizosphere microbiology. Front. Microbiol. 7:565.

Debode, J., Van Hemelrijck, W., Creemers, P., and Maes, M. 2013. Effect of fungicides on epiphytic yeasts associated with strawberry. MicrobiologyOpen 2:482-491.

Dobin, A., Davis, C. A., Schlesinger, F., Drenkow, J., Zaleski, C., Jha, S. Batut, P., Chaisson, M., and Gingeras, T. R. 2013. STAR: Ultrafast universal RNA-seq aligner. Bioinformatics 29:15-21.

FAOSTAT. 2019. Statistics. Accessed December 1, 2019. Food and Agriculture Organization of the United Nations, Rome. Published online. http://www.fao.org/statistics

Gamir, J., Darwiche, R., Van't Hof, P., Choudhary, V., Stumpe, M., Schneiter, R., and Mauch, F. 2017. The sterol-binding activity of PATHOGENESIS-RELATED PROTEIN 1 reveals the mode of action of an antimicrobial protein. Plant J. 89:502-509.

Gooday, G. W. 1990. The ecology of chitin degradation. Adv. Microb. Ecol. 11:387-430.

Goodstein, D. M., Shu, S., Howson, R., Neupane, R., Hayes, R. D., Fazo, J., Mitros, T., Dirks, W., Hellsten, U., Putnam, N., and Rokhsar, D. S. 2012. Phytozome: A comparative platform for green plant genomics. Nucleic Acids Res. 40:D1178-D1186.

Hancock, J., Sjulin, T., and Lobos, G. 2008. Strawberries. Pages 393-437in: Temperate Fruit Crop Breeding. J. F. Hancock, ed. Springer, Dordrecht.

Hasler, K. 2017. Environmental impact of mineral fertilizers: Possible improvements through the adoption of eco-innovations. Master thesis. Wageningen University, Wageningen, The Netherlands.

Hickman, R., Van Verk, M. C., Van Dijken, A. J. H., Mendes, M. P., Vroegop-Vos, I. A., Caarls, L., Steenbergen, M., Van der Nagel, I., Wesselink, G. J., Jironkin, A., Talbot, A., Rhodes, J., De Vries, M., Schuurink, R. C., Denby, K., Pieterse, C. M. J., and Van Wees, S. C. M.
2017. Architecture and dynamics of the jasmonic acid gene regulatory network. Plant Cell 29:2086-2105.

Hirakawa, H., Shirasawa, K., Kosugi, S., Tashiro, K., Nakayama, S., Yamada, M., Kohara, M., Watanabe, A., Kishida, Y., Fujishiro, T., Tsuruoka, H., Minami, C., Sasamoto, S., Kato, M., Nanri, K., Komaki, A., Yanagi, T., Guoxin, Q., Maeda, F., Ishikawa, M., Kuhara, S., Sato, S., Tabata, S., and Isobe, S. N. 2014. Dissection of the octoploid strawberry genome by deep sequencing of the genomes of Fragaria species. DNA Res. 21:169-181.

Huang, A. C., Jiang, T., Liu, Y. X., Bai, Y. C., Reed, J., Qu, B., Goossens, A., Nützmann, H. W., Bai, Y., and Osbourn, A. 2019. A specialized metabolic network selectively modulates Arabidopsis root microbiota. Science 364 eaau6389.

Huang, H., Liu, B., Liu, L., and Song, S. 2017. Jasmonate action in plant growth and development. J. Exp. Bot. 68:1349-1359.

Inderbitzin, P., Ward, J., Barbella, A., Solares, N., Izyumin, D., Burman, P., Chellemi, D. O., and Subbarao, K. V. 2018. Soil microbiomes associated with Verticillium wilt-suppressive broccoli and chitin amendments are enriched with potential biocontrol agents. Phytopathology 108:31-43.

Johnson, J. M., Ludwig, A., Furch, A. C. U., Mithöfer, A., Scholz, S., Reichelt, M., and Oelmüller, R. 2019. The beneficial root-colonizing fungus Mortierella hyalina promotes the aerial growth of Arabidopsis and activates calcium-dependent responses that restrict Alternaria brassicae-induced disease development in roots. Mol. Plant-Microbe Interact. 32:351-363.

Kim, H. J., Chen, F., Wang, X., and Rajapakse, N. C. 2005. Effect of chitosan on the biological properties of sweet basil (Ocimum basilicum L.). J. Agric. Food Chem. 53:3696-3701.

Kim, Y. J., Zhao, Y., Oh, K. T., Nguyen, V. N., and Park, R. D. 2008. Enzymatic deacetylation of chitin by extracellular chitin deacetylase from a newly screened Mortierella sp. DY-52. J. Microbiol. Biotechnol. 18:759-766.

Kõljalg, U., Nilsson, R. H., Abarenkov, K., Tedersoo, L., Taylor, A. F. S., Bahram, M., Bates, S. T., Bruns, T. D., Bengtsson-Palme, J., Callaghan, T. M., Douglas, B., Drenkhan, T., Eberhardt, U., Dueñas, M., Grebenc, T., Griffith, G. W., Hartmann, M., Kirk, P. M., Kohout, P., Larsson, E., Lindahl, B. D., Lücking, R., Martín, M. P., Matheny, P. B., Nguyen, N. H., Niskanen, T., Oja, J., Peay, K. G., Peintner, U., Peterson, M., Põldmaa, K., Saag, L., Saar, I., Schüßler, A., Scott, J. A., Senés, C., Smith, M. E., Suija, A., Taylor, D. L., Telleria, M. T., Weiss, M., and Larsson, K. H. 2013. Towards a unified paradigm for sequence-based identification of fungi. Mol. Ecol. 22:5271-5277.

Kukurba, K. R., and Montgomery, S. B. 2015. RNA sequencing and analysis. Cold Spring Harb. Protoc. 2015:951-969.

Lavell, A. A., and Benning, C. 2019. Cellular organization and regulation of plant glycerolipid metabolism. Plant Cell Physiol. 60:1176-1183.

Lawrence, M., Huber, W., Pagès, H., Aboyoun, P., Carlson, M., Gentleman, R., Morgan, M. T., and Carey, V. J. 2013. Software for computing and annotating genomic ranges. PLOS Comput. Biol. 9:e1003118.

Lee, M. W., Qi, M., and Yang, Y. 2001. A novel jasmonic acid-inducible rice $m y b$ gene associates with fungal infection and host cell death. Mol Plant-Microbe Interact. 14:527-535.

Lee, Y. S., Kim, Y. H., and Kim, S. B. 2005. Changes in the respiration, growth and vitamin $\mathrm{C}$ content of soybean sprouts in response to chitosan of different molecular weights. HortScience 40:1333-1335.

Li, F., Chen, L., Redmile-Gordon, M., Zhang, J., Zhang, C., Ning, Q., and Li, W. 2017. Mortierella elongata's roles in organic agriculture and crop growth promotion in a mineral soil. Land Degrad. Dev. 29: 1642-1651.

Liu, R., Lü, B., Wang, X., Zhang, C., Zhang, S., Qian, J., Chen, L., Shi, H., and Dong, H. 2010. Thirty-seven transcription factor genes differentially respond to a harpin protein and affect resistance to the green peach aphid in Arabidopsis. J. Biosci. 35:435-450.

Lundberg, D. S., Lebeis, S. L., Paredes, S. H., Yourstone, S., Gehring, J., Malfatti, S., Tremblay, J., Engelbrektson, A., Kunin, V., Del Rio, T. G., Edgar, R. C., Eickhorst, T., Ley, R. E., Hugenholtz, P., Tringe, S. G., and Dangl, J. L. 2012. Defining the core Arabidopsis thaliana root microbiome. Nature 488:86-90.

Luypaert, G., Witters, J., Van Huylenbroeck, J., De Clercq, P., De Riek, J., and De Keyser, E. 2017. Induced expression of selected plant defence related genes in pot azalea, Rhododendron simsii hybrid. Euphytica 213: 227.

Madi, L., Wang, X., Kobiler, I., Lichter, A., and Prusky, D. 2003. Stress on avocado fruits regulates $\Delta^{9}$-stearoyl ACP desaturase expression, fatty acid composition, antifungal diene level and resistance to Colletotrichum gloeosporioides attack. Physiol. Mol. Plant Pathol. 62:277-283. 
Meller Harel, Y., Elad, Y., Rav-David, D., Borenstein, M., Shulchani, R., Lew, B., and Graber, E. R. 2012. Biochar mediates systemic response of strawberry to foliar fungal pathogens. Plant Soil 357:245-257.

Nam, M. H., Jeong, S. K., Lee, Y. S., Choi, J. M., and Kim, H. G. 2006. Effects of nitrogen, phosphorus, potassium and calcium nutrition on strawberry anthracnose. Plant Pathol. 55:246-249.

Oksanen, J., Blanchet, G., Kindt, R., Legendre, P., Minchin, P. R., O'Hara, R. B., Simpson, G. L., Solymos, P., Stevens, M. H. M., Szoecs, E., and Wagner, H. 2010. Vegan: Community ecology Package. R package version 2.0-10. Cran-R, Vienna. Published online. http://CRAN.Rproject.org/package=vegan

Özkale, E. 2019. Non-mycorrhizal fungal spectrum of root communities. Pages 77-85 in: Secondary metabolites of plant growth promoting rhizomicroorganisms. H. Sing, C. Keswani, M. Reddy, E. Royano, and C. García-Estrada, eds. Springer Nature, Singapore.

Paulus, A. O. 1990. Fungal diseases of strawberry. HortScience 25:885-889.

Petrasch, S., Knapp, S. J., van Kan, J. A. L., and Blanco-Ulate, B. 2019. Grey mould of strawberry, a devastating disease caused by the ubiquitous necrotrophic fungal pathogen Botrytis cinerea. Mol. Plant Pathol. 20: 877-892.

Postma, J., and Schilder, M. T. 2015. Enhancement of soil suppressiveness against Rhizoctonia solani in sugar beet by organic amendments. Appl. Soil Ecol. 94:72-79.

Pritts, M., Heidenreich, C., McDermott, L., and Miller, J. 2015. Berry Soil and Nutrient Management-A Guide for Educators and Growers. Cornell University, Ithaca, NY, U.S.A.

Quast, C., Pruesse, E., Yilmaz, P., Gerken, J., Schweer, T., Yarza, P., Peplies, J., and Glöckner, F. O. 2013. The SILVA ribosomal RNA gene database project: Improved data processing and web-based tools. Nucleic Acids Res. 41 (D1):D590-D596.

Radwan, M. A., Farrag, S. A. A., Abu-Elamayem, M. M., and Ahmed, N. S. 2012. Extraction, characterization, and nematicidal activity of chitin and chitosan derived from shrimp shell waste. Biol. Fertil. Soils 48: 463-468.

Rafferty, S. M., Murphy, J. G., and Cassells, A. C. 2003. Lytic enzyme activity in peat is increased by substrate amendment with chitin: Implications for the control of Phytophthora fragariae in Fragaria vesca. Folia Geobot. 38:139-144.

Ramírez, M. A., Rodríguez, A. T., Alfonso, L., and Peniche, C. 2010. Chitin and its derivatives as biopolymers with potential agricultural applications. Biotecnología Aplicada 27:270-276.

Robinson, M. D., McCarthy, D. J., and Smyth, G. K. 2010. edgeR: A Bioconductor package for differential expression analysis of digital gene expression data. Bioinformatics 26:139-140.

Ruan, J., Zhou, Y., Zhou, M., Yan, J., Khurshid, M., Weng, W., Cheng, J., and Zhang, K. 2019. Jasmonic acid signaling pathway in plants. Int. J. Mol. Sci. 20:2479.

Sánchez-Vallet, A., Mesters, J. R., and Thomma, B. P. H. J. 2015. The battle for chitin recognition in plant-microbe interactions. FEMS Microbiol. Rev. 39:171-183.

Sarathchandra, S. U., Watson, R. N., Cox, N. R., di Menna, M. E., Brown, J. A., Burch, G., and Neville, F. J. 1996. Effects of chitin amendment of soil on microorganisms, nematodes, and growth of white clover (Trifolium repens L.) and perennial ryegrass (Lolium perenne L.). Biol. Fertil. Soils 22:221-226.
Schandry, N. 2017. A practical guide to visualization and statistical analysis of $R$. solanacearum infection data using R. Front. Plant Sci. 8:623.

Seo, P. J., and Park, C. M. 2010. MYB96-mediated abscisic acid signals induce pathogen resistance response by promoting salicylic acid biosynthesis in Arabidopsis. New Phytol. 186:471-483.

Sharp, R. G. 2013. A review of the applications of chitin and its derivatives in agriculture to modify plant-microbial interactions and improve crop yields. Agronomy (Basel) 3:757-793.

Supek, F., Bošnjak, M., Škunca, N., and Šmuc, T. 2011. REVIGO summarizes and visualizes long lists of gene ontology terms. PLoS One 6:e21800.

Taj, G., Agarwal, P., Grant, M., and Kumar, A. 2010. MAPK machinery in plants: Recognition and response to different stresses through multiple signal transduction pathways. Plant Signal. Behav. 5:1370-1378.

Tao, T. 2008. Standalone BLAST Setup for Unix. Accessed October 7, 2019. National Center for Biotechnology Information, Bethesda, MD, U.S.A. Published online. https://www.ncbi.nlm.nih.gov/books/NBK52640

Thimm, O., Bläsing, O., Gibon, Y., Nagel, A., Meyer, S., Krüger, P., Selbig, J., Müller, L. A., Rhee, S. Y., and Stitt, M. 2004. MAPMAN: A userdriven tool to display genomics data sets onto diagrams of metabolic pathways and other biological processes. Plant J. 37:914-939.

Van Bel, M., Diels, T., Vancaester, E., Kreft, L., Botzki, A., Van de Peer, Y., Coppens, F., and Vandepoele, K. 2018. PLAZA 4.0: An integrative resource for functional, evolutionary and comparative plant genomics. Nucleic Acids Res. 46 (D1):D1190-D1196.

Vandecasteele, B., Debode, J., Willekens, K., and Van Delm, T. 2018. Recycling of $\mathrm{P}$ and $\mathrm{K}$ in circular horticulture through compost application in sustainable growing media for fertigated strawberry cultivation. Eur. J. Agron. 96:131-145.

Vervoort, M., Melis, P., Stoffels, K., and Van Delm, T. 2017. Comparing an integrated pest management with a chemical control strategy in multiple strawberry cultivations. Abstract. 3rd International Strawberry Congress. Strawberries on demand, the consumer rules the future. Antwerp, Belgium.

Walley, J. W., Kliebenstein, D. J., Bostock, R. M., and Dehesh, K. 2013. Fatty acids and early detection of pathogens. Curr. Opin. Plant Biol. 16:520-526.

Windram, O., Madhou, P., McHattie, S., Hill, C., Hickman, R., Cooke, E., Jenkins, D. J., Penfold, C. A., Baxter, L., Breeze, E., Kiddle, S. J., Rhodes, J., Atwell, S., Kliebenstein, D. J., Kim, Y. S., Stegle, O., Borgwardt, K., Zhang, C., Tabrett, A., Legaie, R., Moore, J., Finkenstadt, B., Wild, D. L., Mead, A., Rand, D., Beynon, J., Ott, S., BuchananWollaston, V., and Denby, K. J. 2012. Arabidopsis defense against Botrytis cinerea: Chronology and regulation deciphered by highresolution temporal transcriptomic analysis. Plant Cell 24:3530-3557.

Winkler, A. J., Dominguez-Nuñez, J. A., Aranaz, I., Poza-Carrión, C., Ramonell, K., Somerville, S., and Berrocal-Lobo, M. 2017. Short-chain chitin oligomers: Promoters of plant growth. Mar. Drugs 15:40.

Xin, Z., Wang, A., Yang, G., Gao, P., and Zheng, Z. L. 2009. The Arabidopsis A4 subfamily of lectin receptor kinases negatively regulates abscisic acid response in seed germination. Plant Physiol. 149:434-444.

$\mathrm{Xu}, \mathrm{X}$., Robinson, J., and Else, M. A. 2013. Effects of nitrogen input and deficit irrigation within the commercial acceptable range on susceptibility of strawberry leaves to powdery mildew. Eur. J. Plant Pathol. 135:695-701.

Yu, G., Wang, L. G., Han, Y., and He, Q. Y. 2012. clusterProfiler: An R package for comparing biological themes among gene clusters. OMICS $16: 284-287$. 